\title{
The Empirical Meaning of The Use of Soil Dust for Ritual Purification/Cleaning in Islamic Teachings in Relation to Chemical Composition and Adsorption Properties of Soil Dust
}

\author{
Dede Suhendar ${ }^{1}$, Riza Andrian ${ }^{1}$, Yunita ${ }^{1}$, Humaira Virda Ayun ${ }^{2}$, Hasniah Aliah ${ }^{3}$, Tety \\ Sudiart $^{1}$, dan Asep Supriadin ${ }^{1}$ \\ \{dede.suhendar@uinsgd.ac.id\} \\ Dept. of Chemistry, Faculty of Science and Technology, UIN Sunan Gunung Djati, Jl. A.H. Nasution \\ No. 105, Bandung 40614, Indonesia ${ }^{1}$ \\ Dept. of Biology Education, Faculty of Tarbiyah and Teachers Training, IAIN Syekh Nurjati, Jl. \\ Perjuangan By Pass Sunyaragi Cirebon 45132, Indonesia ${ }^{2}$ \\ Dept. of Physics, Faculty of Science and Technology, UIN Sunan Gunung Djati, Jl. A.H. Nasution \\ No. 105, Bandung 40614, Indonesia ${ }^{3}$
}

\begin{abstract}
Ritual practices in religion were generally studied in social science contexts. However, soil dust (SD) as a material for cleaning ritually unclean substances in Islamic teaching attracts attention in the chemical science context. Substantially, unclean substances are sourced more from organic matters (OM) than inorganic matters. This study objected to understand the purity practices of Muslims using SD that correlated with the levels of $\mathrm{Si}, \mathrm{Al}, \mathrm{Fe}$, and $\mathrm{Ca}$ in adsorbing methylene blue as a representation of unclean substance and $\mathrm{CuSO}_{4}$ as a non-unclean substance. This study included experiments with SDs $(0.02 \mathrm{~g})$ that was contacted with $\mathrm{MB}(10 \mathrm{~mL}, 50 \mathrm{ppm})$ and $\mathrm{CuSO}_{4}$ $\left(20 \mathrm{~mL}, 100 \mathrm{ppm}\right.$ as $\mathrm{Cu}^{2+)}$ solutions with stirring for 2 minutes at room temperature. The experiment conditions, $\mathrm{MB}$ and $\mathrm{Cu}^{2+}$ were adsorbed in the range $70.9-97.37 \%$ and $45.43-73.53 \%$, respectively. Using the contact time, the range of adsorption capacities of SD samples was $7.09-9.74$ and $50.88-73.04 \mathrm{mg}$ per $\mathrm{g}$ of SD, respectively. The power adsorption of $\mathrm{SD}$ against $\mathrm{MB}$ and $\mathrm{CuSO}_{4}$ tend to be influenced by the content of the mentioned elements. In addition, the calcination treatment decreased the percentage of adsorbed $\mathrm{MB}$ and $\mathrm{CuSO}_{4}$ so that the $\mathrm{OM}$ content in soil dust has a direct role in its adsorption power. From the results, the practice of ritual purity of Muslims using soil dust can be explained through the adsorption mechanism which is directly influenced by the chemical nature of the soil dust.
\end{abstract}

Keywords: Soil Dust, Adsorption, Dyestuffs, Calcination, Organic Matter, Unclean Matter.

\section{Introduction}

The chemical content of soil dust is not much different from the surrounding soil content [1]. Although soil dust has a mineral content similar to soil [2] [3] [4], the studies that have been carried out are largely motivated by dangers that can interfere with health [5] [6] [7] [8] [9] [10] [11] [12] [13]. For Muslims who understand the rules of Islam for their women in 
dressing, ground dust serves to purify the unclean clothes that are attached to the lower end of the cloth that reaches the ground [14]. In addition, the dust of land or land by the Muslim community is used for several activities involving worship, such as cleaning dog saliva from a vessel and cleaning the face and hands rather than ablution if water is difficult to obtain [15]. Meanwhile, the main mineral content from the soil such as clay has been known as an adsorbent [4]. Therefore, the phenomenon of land and dust is very important to be investigated in connection with its ability to clean up najis (ritually unclean) because this is a matter of worship for Muslims who constitute the majority of Indonesia's population, especially in worship practices that involve the use of soil dust.

Najis types and sources are quite diverse, such as the contents of dog saliva, blood, all carcasses except grasshoppers and marine animals, animal and human excrement [1]. Najis (unclean matters) have general characteristics that are dominated by organic matter. Meanwhile, land characterized always contains silicon and aluminum in the form of silica, silicates and aluminosilicates. The presence of topsoil and fulvate in the soil indicates that the main soil compounds can bind organic matter [3]. Apart from other sources, organic matter contained in soil dust also comes from organic substances in the soil [16] [17]. The organic matter contained in the soil has represented most types of organic matter based on the framework, functional groups, and its elements [18] [19].

From the explanation above, the function of soil or soil dust can purify najis can be understood empirically through the approach of the phenomenon of adsorption of isotherms, soil dust or soil as an adsorbent, while najis substances are adsorbates. Therefore, to understand soil or soil dust as an unclean washing medium can be performed by contacting it with a single organic substance. Single organic substance which is often used as models of adsorbates is methylene blue (MB), such as their contact with zeolite [20] [21] [22] [23] [24] [25] [26] [27] [28] [29], kaolin [20], activated carbon [30] [31] [32], and agricultural wastes [33] [34] [35] [36] [37].

The soil content is dominated by silicon, aluminum, iron, and calcium oxides, so that these four oxides are ranked in the top 5 in the earth's crust [38]. In general, minerals from the main elements are directly responsible for binding organic matter in the soil [39] through three types of interactions, namely van der Walls, cation bridges, and complex formation [40]. Two elements that vary greatly in their mineral types are $\mathrm{Si}$ and $\mathrm{Al}$, namely silicate and aluminosilicate minerals, while iron and calcium minerals are less diverse. The presence of a combination of these oxides will be complicated enough to evaluate their effect on their adsorption ability if we consider various types of minerals, so simplification is needed by only paying attention to the levels of the elements that make up the oxides. Although calcium has a relatively large percentage level in soil, several studies have shown that organic matter can be adsorbed by soil in relation to the presence of three elements, namely Si, Al, and Fe [41] [42]. Meanwhile, the stability of organic matter in the soil is only influenced by $\mathrm{Al}$ and $\mathrm{Fe}$ [43] or Fe only [44].

As solids, soil and soil dust can act as an adsorbent which is certainly influenced by all elements that actually contribute to the formation of soil solids that have low to very low solubility in water. Calcium which can be available as calcium carbonate or calcium silicate solids is predicted to have a direct role in the properties of soil adsorbents. The involvement of calcium has been proven [63], its presence shows its role in increasing the adsorption capacity of the soil [45].

The complexity of the soil mineral content and variations in its composition greatly complicates the study of the role of each mineral, so a simple method is needed by simply taking the relationship between the four elements that form soil solids, $\mathrm{Si}, \mathrm{Al}, \mathrm{Fe}$, and $\mathrm{Ca}$, with 
organic matter adsorbed. Based on the background above, this study aims to examine the presence of organic matter adsorption in soil dust, using MB as a model of organic matter. The ability of soil dust to adsorb MB will also be compared limited to soil and building wall dust, and $\mathrm{MB}$ adsorbate will also be compared with $\mathrm{CuSO}_{4}$ solution. The results of this study are expected to explain soil dust as a purification medium in Muslim worship, so that Muslims not only accept religious teachings, but are also supported by scientific explanations. In addition, the results of this study also have the potential to be developed in increasing the use of soil dust through technical studies to change the composition of the main elements through acid or alkaline treatment as is usually done with materials containing identical elements, such as clay [46] [47] and zeolite [48] [49].

\section{Method}

To understand the empirical meaning of the purpose of using soil dust for purification, the chemical approach used the mechanism and adsorption model to prove soil dust as a good adsorbent. Meanwhile, the problem of najis model was simplified as the proportion of organic material contribution. The adsorption or absorption interaction model was carried out using a hydrophilic-hydrophobic interaction gradation approach. In addition to the functional group explanation, understanding soil dust as an adsorbent will also use an activity approach on its surface area.

\subsection{Material}

The materials used in this study were demineralized water $(\mathrm{pH}=7.09$ and electrical conductivity $=8.38 \mu \mathrm{S} / \mathrm{cm}$ ), methylene blue (Merck), $\mathrm{CuSO}_{4} \cdot 5 \mathrm{H}_{2} \mathrm{O}$ (Merck). The dust samples used were soil dust, soil, and building wall dust. The equipment used included magnetic stirrer, hot plate, porcelain cup, oven, baking sheets, spray bottle, filter paper (pore size 0.45 $\mu \mathrm{m})$, valkon tubes (15 and $50 \mathrm{~mL}$ ), centrifuge, 100 mesh sieve, analytic balance, stirring rod, glass funnel, $10 \mathrm{~mL}$ volumetric pipette, $5 \mathrm{~mL}$ measuring pipette, $1 \mathrm{~mL}$ measuring pipette, bulb, watch glass, pestle, mortar, volumetric flask $(25$ and $100 \mathrm{~mL})$, spatula, beaker glass $(50$, 100,600 and $1000 \mathrm{~mL}$ ), vortex stirrer, and pipette drops.

\subsection{Soil dust, soil, and building wall dust}

Samples of soil dust, soil, and building wall dust were obtained from several regencies in West Java, Indonesia. The soil dust samples used include floor dust from four dwellings, soil dust from a carpark, soil dust from under a stilt house, soil dust from excavated land, mosque floor dust, and bus vehicle interior dust. Six soil samples were obtained from around Sumedang and Bandung Regencies, and three building wall dust samples were obtained from Karawang, Subang, and Purwakarta Regencies. All samples of the three types of dust were cleaned of objects that are not related to the characteristics of each type of dust. Each sample was washed with demineralized water $(1 \mathrm{~g}$ sample : $2 \mathrm{~mL}$ of water) by stirring at a speed of $700 \mathrm{rpm}$ for 1 hour and then separated by decantation. The procedure was carried out in 3 repetitions. Next, each separated solid was dried at $120{ }^{\circ} \mathrm{C}$ for 3 hours, then finely ground and sieved with a 100 mesh size sieve. The soil dust samples produced from sieving were then used in the adsorption experiments, analyses, and characterizations. 


\subsection{Adsorption experiments}

The adsorption experiments were carried out without temperature control, but the room temperature at the time of the experiment (recorded varied in the range $25-26{ }^{\circ} \mathrm{C}$ ). The adsorption experiments were divided into two parts, namely the main adsorption experiments and the isotherm adsorption experiments. The main and most complete adsorption experiments were only carried out on soil dust, namely by stirring $0.02 \mathrm{~g}$ of soil dust samples with $10 \mathrm{~mL}$ of methylene blue (MB) $50 \mathrm{ppm}$ at $100 \mathrm{rpm}$ for 2 minutes, then centrifuged at $4000 \mathrm{rpm}$ for 5 minutes. Experiments were also carried out using samples of calcined soil dust and also using $\mathrm{CuSO}_{4}$ adsorbates. Experiments on the $\mathrm{MB}$ isotherm adsorption on soil dust were also carried out to investigate the isotherm adsorption model. Experiments using soil adsorbents and building wall dust were carried out limitedly and carried out as a comparison in the adsorption ability using 2 minutes of contact time.

\subsection{Characterization and analysis}

The mineralogy of soil dust samples was determined by the interpretation of X-ray diffraction peak patterns from scanning $2 \theta$ at $5-70^{\circ}$ with X-ray diffractometers (Shimadzu XRD-7000) while elemental analysis was determined by X-ray fluorescence spectrometer (Rigaku Supermini2000). Characterization of surface area and pore distribution of soil dust particles carried out successively through BET (Brunauer-Emmet-Teller) and BJH (BarrettJoyner-Halenda) adsorption-desorption method using nitrogen as an adsorbate (Quantachrome Autosorb Instruments). Making a standard curve and determining the concentration of MB solution before and after the adsorption treatment was determined by using the ultravioletvisible spectrophotometer (Agilent Technologies Cary 60) at $\lambda_{\max }=664 \mathrm{~nm}$, while for the $\mathrm{CuSO}_{4}$ solution using an atomic absorption spectrophotometer (Agilent 200 Series AA) at $\lambda=$ $324.8 \mathrm{~nm}$.

\subsection{Effect of the content of $\mathrm{Si}, \mathrm{Al}, \mathrm{Fe}$, and $\mathrm{Ca}$ in absorbing dissolved methylene blue}

The possible effects of the composition of the main elements in soil dust were tested by linear and non-linear regression, the relationship between the percentage of MB solution absorbed with some elemental composition statements that have been present in the literature and in addition to this study. Two statements about the element composition of the adsorbent in the literature used in this study were the mole ratio of $\mathrm{Si} / \mathrm{Al}$ which is often used in zeolite aluminosilicate [50] and $\mathrm{Si} /(\mathrm{Al}+\mathrm{Fe})$ used in soil sample [51]. Another element considered was $\mathrm{Ca}$ because of the element abundant on the crust. In addition to the mole units, this study also used the percentage level of elements in the collective statement of the quantity. These analysis of regression had also been perfomed more limited to the results of contact with soil powder and building wall dust, also additional adsorbate, $\mathrm{CuSO}_{4}$ solutions. 


\section{Result and Discussion}

\subsection{The mineral content in soil dust and the order of adsorption ability against methylene blue}

The soil dust samples in this study has various mineral compositions. Based on X-ray diffraction patterns, generally the types of silica and aluminosilicate minerals were detected in all samples by adsorbing MB in the range of $70.90-97.37 \%$ in 2 minutes contact time (Figure 1), using $50 \mathrm{ppm} \mathrm{MB}$ of $10 \mathrm{~mL}$ and each dust sample soil $0.05 \mathrm{~g}$. As far as we know, the contact time used in this study was the shortest contact time from the contact time used in the adsorption studies using an adsorbent that has a mineralogy relationship close to the soil, such as kaolin (5 minutes) [20], zeolite A (5 minutes) [20], and zeolit X (1 hour) [24]. This shortest time was chosen because the activities associated with tayamum and the interaction of soil dust with women's clothing are also quite short. But using this short amount of time, most of the MB mass has been absorbed. To make it easier in comparison, the adsorption capacity of the adsorbent was then expressed in \% adsorbates adsorbed from the solution with the same concentration, volume, weight of the adsorbent, and contact time.

By sequencing soil dust samples based on their adsorption power to MB, we did not see a mineralogical relationship with dust adsorption power (Figure 1). The sharpness of the diffraction peak which can describe semiquantatively the crystallinity or mineral content of soil dust cannot be easily related to the strength of adsorption. The element of Fe which is quite dominant in its abundance in the earth's crust was difficult to detect using X-ray diffraction, as well as the element $\mathrm{Ca}$, whose abundance is adjacent to the element $\mathrm{Fe}$, except in DR2 and DR3 samples (The sample code information and the results of elemental analysis of all samples of soil dust, soil, and building wall dust are presented in Table 5).
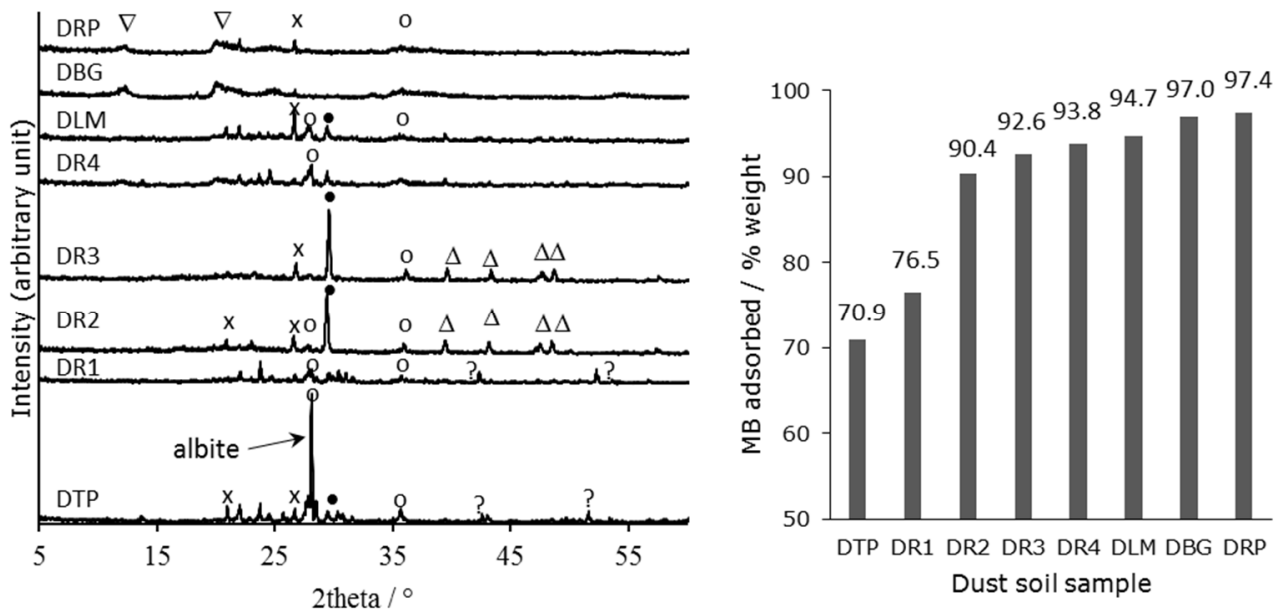

Figure. 1. The diffractogram pattern of the soil dust samples (left picture) and the MB adsorbed weight percentage (right picture) are successively sorted from the smallest to the largest percentage, namely soil dust from mosque parking lot (DTP), floor dust from four houses (DR1, DR2, DR3 and DR4), mosque floor dust (DLM), soil dust from excavated soil (DBG), and soil dust from under a stilt house (DRP). The phases detected in this sample are quartz $(\mathrm{x})$, three types of aluminosilicate minerals $(\cdot, \mathrm{o}$, and $\nabla)$ that have not been specifically determined for their mineral phase, calcium carbonate $(\Delta)$, and unknown phases (?) 
The presence of mineralogical differences with methylene blue adsorption by soil dust can be seen as shown by the results of interpretation of X-ray diffraction patterns in Figure 1. This comparison did not involve two samples, DPB and DPT, because their amount were not enough for XRD analysis and several other tests. As shown in the figure, the vehicle parking dust sample (DTP) ranks lowest in absorbing MB. The results of the diffraction peak analysis in the DTP sample at $2 \theta=28.15^{\circ}$ and adjacent ones showed that DTP had the main content of the albite phase. Together with quartz, these aluminosilicates are known to have the lowest specific surface area among the silicate minerals [52]. Therefore we can only draw conclusions about the relationship of the mineral phase with adsorption power in only $\mathrm{MB}$ in the case of this DTP sample.

\subsection{The relationship of the element abundances in adsorbing methylene blue}

The absence of a relationship between the mineral phase and MB adsorption on soil dust (Figure 1) illustrates the complexity of the various causes of adsorption in soil dust, so it is not only related to the mineral phase, quantity, and crystallinity. However, the complexity of various single or combination phases containing silicon and aluminum elements can be evaluated using the mole ratio of elements, such as the mole ratio of $\mathrm{Si} / \mathrm{Al}[50]$ or $\mathrm{Si} /(\mathrm{Al}+\mathrm{Fe})$ [51]. Using the mole ratio $\mathrm{Si} /(\mathrm{Al}+\mathrm{Fe})$, the relationship between this mole ratio in the case of very chemically different types of samples such as bentonite, red soil, and kaolinite [51]. We conducted a number of regression tests between the percentage of $\mathrm{MB}$ absorbed and the composition of the main chemical elements of soil dust, in the mole ratio or the percentage ratio of weight of $\mathrm{Si} / \mathrm{Al}$ and $\mathrm{Si} /(\mathrm{Al}+\mathrm{Fe})$. However, regression using $\mathrm{Si} / \mathrm{Al}$ ratios yielded very small $\mathrm{R}^{2}$ and vice versa in the form of $\mathrm{Si} /(\mathrm{Al}+\mathrm{Fe})$ better as presented in Table 1 . This table also shows significant differences between regression of all samples and regression without sample DR1.

Table 1. $\mathrm{R}^{2}$ values of the plot between the percentage of methylene blue (MB) adsorbed with the statements of the chemical composition of the main elements of soil dust.

\begin{tabular}{|c|c|c|c|c|c|}
\hline \multirow{3}{*}{ No. } & \multirow{3}{*}{$\begin{array}{l}\text { Statement of the } \\
\text { amount } \\
\text { chemicals } \\
\text { moles or levels } \\
(\% \mathrm{w} / \mathrm{w})\end{array}$} & \multicolumn{4}{|c|}{$\begin{array}{l}\text { The values of } \mathrm{R}^{2} \text { in polynomial } 2 \text { with a different statement of the quantity } \\
\text { of chemical elements }\end{array}$} \\
\hline & & \multicolumn{2}{|c|}{ By including the DR1 sample } & \multicolumn{2}{|c|}{$\begin{array}{l}\text { without including the } \\
\text { DR1 sample }\end{array}$} \\
\hline & & mol & kadar & mol & Kadar \\
\hline 1 & $\mathrm{Si} / \mathrm{Al}$ & 0.241 & 0.241 & 0.256 & 0.256 \\
\hline 2 & $\mathrm{Si} /(\mathrm{Al}+\mathrm{Fe})$ & 0.458 & 0.514 & 0.788 & 0.897 \\
\hline 3 & $(\mathrm{Si}-\mathrm{Al}) / \mathrm{Fe}$ & 0.535 & 0.535 & 0.891 & 0.895 \\
\hline 4 & $(\mathrm{Si}-\mathrm{Al}) / \mathrm{Ca}$ & 0.104 & 0.106 & 0.110 & 0.113 \\
\hline 5 & $(\mathrm{Si}-\mathrm{Al}) /(\mathrm{Fe}+\mathrm{Ca})$ & 0.535 & 0.639 & 0.607 & 0.787 \\
\hline
\end{tabular}

As shown in Table 1, there are three forms of elemental composition statements that were better than $\mathrm{Si} / \mathrm{Al}$, namely $\mathrm{Si} /(\mathrm{Al}+\mathrm{Fe}),(\mathrm{Si}-\mathrm{Al}) / \mathrm{Fe}$, and $(\mathrm{Si}-\mathrm{Al}) /(\mathrm{Fe}+\mathrm{Ca})$ if not included in the sample DR1. In the table it can also be seen that the statement of the number of elements in the form of a percentage weight was better than the form of the mole. Calcium was involved in the percentage ratio $(\mathrm{Si}-\mathrm{Al}) /(\mathrm{Fe}+\mathrm{Ca})$ because this element was still quite dominant in quantity based on the results of elemental analysis, but not better than not including it, (Si$\mathrm{Al} / \mathrm{Fe}$. The addition of the involvement of elements other than $\mathrm{Si}, \mathrm{Al}, \mathrm{Fe}$, and $\mathrm{Ca}$ were not 
have a further significant effect on changes in the value of $\mathrm{R}^{2}$ (not shown in this text). The quantity statement form of the elements in Table 1 is the quantity statement form of the selected elements resulting in a polynomial regression 2 which gives the highest $\mathrm{R}^{2}$ value. The relationship involving levels of $\mathrm{Si}, \mathrm{Al}$, and $\mathrm{Fe}$ was greater than involving $\mathrm{Ca}$, quite in line with the results of Mikutta et al. which was not consider the involvement of $\mathrm{Ca}$ in the soil in binding organic matter in soil [18].

Of several other elements that have lower amounts of lower calcium or iron, $\mathrm{K}, \mathrm{Mg}, \mathrm{Na}$, and $\mathrm{Ti}$ [53], only $\mathrm{Mg}$ and $\mathrm{Ti}$ chemically will contribute to a more permanent soil mass than $\mathrm{K}$ and $\mathrm{Na}$. Mg compounds are more likely to contribute to the mass of soil dust if they are not in the form of nitrate salts, whereas Ti has too little abundance, so the effect can be ignored. $\mathrm{K}$ and $\mathrm{Na}$ can also be ignored because they are only in the form of ions which dissolve and can be exchanged between cations dissolved in the soil.

By comparing the values of $\mathrm{R} 2$ in Table 1, we can see that from 10 soil dust samples there is one sample of soil dust which has a very significant effect in reducing the coefficient of determination $\left(\mathrm{R}^{2}\right)$, namely DR1. Among other samples, the DR1 sample was the sample that had the most different possibility in its chemical composition. DR1 was a sample of soil dust accumulated from the floor of the house from the location of the DR2 sampling. It is possible that the chemical composition of doormat dust in this study is more complex than ordinary floor dust because dust doormats are usually made of special materials and specially formed which serve to accumulate various types of impurities.

Table. 2 The ratio of the content of the main elements in soil dust

\begin{tabular}{lccccccc}
\hline & \multicolumn{3}{c}{ Elemental content ratio in soil dust samples } \\
Sample & \multicolumn{9}{c}{1} \\
\cline { 2 - 7 } code & \multicolumn{3}{c}{ uncalcined } & \multicolumn{3}{c}{ calcinedi $^{2}$} \\
\cline { 2 - 7 } & $\mathrm{Al}$ & $\mathrm{Fe}$ & $\mathrm{Ca}$ & $\mathrm{Al}$ & $\mathrm{Fe}$ & $\mathrm{Ca}$ \\
\hline DPB & 0.457 & 0.794 & 0.472 & & & \\
DPT & 0.461 & 0.765 & 0.374 & & & \\
DPK & 0.569 & 0.672 & 0.075 & 0.548 & 0.641 & 0.073 \\
DPG & 0.781 & 0.729 & 0.010 & 0.812 & 0.738 & 0.009 \\
DPP & 0.349 & 0.414 & 0.446 & 0.349 & 0.414 & 0.446 \\
DPM & 0.349 & 0.657 & 1.100 & 0.338 & 0.447 & 0.881 \\
DPR1 & 0.412 & 0.697 & 0.340 & 0.407 & 0.452 & 0.447 \\
DPR2 & 0.511 & 0.547 & 0.429 & 0.512 & 0.496 & 0.389 \\
DPR3 & 0.380 & 0.553 & 0.754 & 0.380 & 0.453 & 0.643 \\
DPR4 & 0.329 & 0.662 & 2.230 & 0.335 & 0.433 & 1.821 \\
\hline & 0.460 & 0.649 & 0.623 & 0.460 & 0.509 & 0.589
\end{tabular}

${ }^{1}$ Ratio of elemental content was normalized to $\mathrm{Si}$, ratio of content of $\mathrm{Si} / \mathrm{Si}=1$; ${ }^{2}$ The elements of the calcined DPB and DPT were not analyzed because their quantities were limited.

Based on the results of the elemental analysis shown in Table 2, we found no strange elements in the DR1 sample compared to other samples. Therefore we estimate that the 
magnitude of the deviation of the DR1 sample from regression comes from the saturation of organic matter. The large amount of organic matter from samples similar to DR1 still needs to be studied further, by examining the comparison of the average content of soil organic matter on doormats with more representative soil dust.

In this study we did not analyze all the elements and organic substances specifically, but only analyzed non-organic materials which have the greatest influence on the absorption capacity of soil dust, namely the main elements $\mathrm{Si}, \mathrm{Al}, \mathrm{Fe}$, and $\mathrm{Ca}$. We performed a regression comparison of the effects of the chemical composition of the four elements on two conditions of dust samples, namely between those not calcined (only dried at $120{ }^{\circ} \mathrm{C}$ ) and those calcined (heated at $550{ }^{\circ} \mathrm{C}$ ). In this comparison, the DR1 sample was involved and the DPB and DPT samples were not involved. Excluding DPB and DPT samples for technical reasons, the number of both calcined samples was not sufficiently available. Furthermore, the results of the comparison are presented in Table 3. In the table it can be seen that several regressions involving $\mathrm{Ca}$ elements (no. 5, 7, 8, and 9) in calcined soil dust samples generally have a correlation above the overall regression average. However, studies on the influence of $\mathrm{Ca}$ elements are still limited because the type of sample is still limited to the use of samples dominated by $\mathrm{CaCO}_{3}$ as in limestone [54] [55], so it is still difficult to find a comparison of the results of this study with literature.

Although in general organic compounds in soils are dominated by humus, the range of functional groups of organic matter (based on the ratio of levels between $\mathrm{O}, \mathrm{N}$ and $\mathrm{H}$, and $\mathrm{C}$ ) in soils is quite diverse with their ecological differences (Seifert et al., 2016), therefore calcination treatment was expected to ensure soil dust was free of most organic substances, leaving most or all components of soil dust dominated by silicon, aluminum, iron and calcium oxides. From Table 3, it can be seen that most adsorption is suitable $\left(\mathrm{R}^{2}>0.5\right)$ with various forms of chemical composition statements involving levels of two to three elements from $\mathrm{Si}$, $\mathrm{Al}, \mathrm{Fe}$, and $\mathrm{Ca}$ if soil dust does not contain organic matter. The involvement of four elements at once (as $(\mathrm{Si}-\mathrm{Al}) /(\mathrm{Fe}+\mathrm{Ca}))$ significantly decreases the value of $\mathrm{R}^{2}$. With the results of this regression, the calcined soil dust adsorption power was determined from a combination of 2-3 elements from the variation of the four element mentioned.

Table. 3 Comparison of the R2 value in the polynomial 2 regression of the adsorbed MB to the quantity statement of the chemical composition of the selected elements.

\begin{tabular}{clcc}
\hline No. & $\begin{array}{l}\text { Statement of } \\
\text { quantity of } \\
\text { chemical } \\
\text { composition }\end{array}$ & $\begin{array}{l}\mathrm{R}^{2} \text { values in the polynomial 2 regression of } \mathrm{MB} \text { adsorbed against the } \\
\text { quantity statement of the chemical composition of the elements (in \% w/w) }\end{array}$ \\
\cline { 2 - 3 } & $\begin{array}{c}\text { Without } \\
\text { calcination }\end{array}$ & With calcination \\
\hline 2 & $\mathrm{Si} / \mathrm{Al}$ & 0,2576 & 0,7115 \\
3 & $\mathrm{Si} /(\mathrm{Al}+\mathrm{Fe})$ & 0,5214 & 0,8127 \\
4 & $(\mathrm{Si}-\mathrm{Al}) / \mathrm{Fe}$ & 0,2289 & 0,6859 \\
5 & $(\mathrm{Si}-\mathrm{Al}) / \mathrm{Ca}$ & 0,5407 & 0,7889 \\
6 & $(\mathrm{Si}-\mathrm{Al}) /(\mathrm{Fe}+\mathrm{Ca})$ & 0,1290 & 0,9176 \\
7 & $\mathrm{Ca}-\mathrm{Al}$ & 0,6402 & 0,2209 \\
8 & $(\mathrm{Ca}-\mathrm{Al}) / \mathrm{Fe}$ & 0,1923 & 0,8594 \\
9 & $(\mathrm{Ca}-\mathrm{Fe}) / \mathrm{Al}$ & 0,2019 & 0,8214 \\
\hline
\end{tabular}

From a number of regressions in Tables 1 and 3 , the statement of the chemical composition as $\mathrm{Si} /(\mathrm{Al}+\mathrm{Fe})$ is quite good in determining the relationship of soil dust adsorption 
power. Tests of soil excavated from 6 different places also showed consistency in the effect of chemical composition as $\mathrm{Si} /(\mathrm{Al}+\mathrm{Fe})$. As shown in Figure 3, after a number of regression tests use the quantity statement as shown in Table $3, \mathrm{Si} /(\mathrm{Al}+\mathrm{Fe})$ is a form of quantity statement of the elements that have the highest $\mathrm{R}^{2}$. Therefore, $\mathrm{Si} /(\mathrm{Al}+\mathrm{Fe})$ is the best form of quantity statement in the case of soil or soil dust.

Based on the pattern of quantity of adsorbates adsorbed by soil and soil dust (Figure 2), it is clear that there was an effect of the composition of absorbent elements expressed in the ratio of $\mathrm{Si} /(\mathrm{Al}+\mathrm{Fe})$ levels. Although it did not involve the number and type of representative samples, as far as we know, this phenomenon was only found for the first time. The idea of the relationship between the strength of adsorption and the chemical composition of minerals $\mathrm{Si} /(\mathrm{Al}+\mathrm{Fe})$ in the soil or its mixture come from Shen, but Shen used a mole ratio and only involved 3 samples, even then in a linear relationship [51]. Here we showed a very diverse mineralogical sample that has a non-linear correlation, namely a polynomial 2 . This non-linear relationship had been predicted by Stockmann et al. which described the content of organic matter in soil as a function of increasing the percentage of clay (aluminosilicate) to sand in a non-linear regression relationship as well [56]. The phenomenon of this nonlinear relationship had also been found in the case of other studies, that an increase in organic matter entering the soil is followed by destabilization which is faster over time producing the final $\mathrm{CO}_{2}$ product [57].
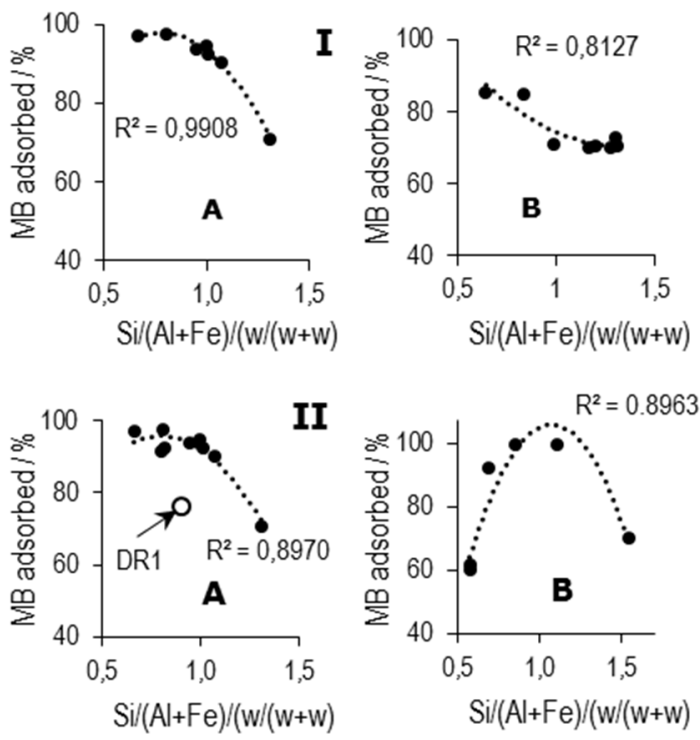

Figure. 2. Plot percentage of methylene blue (MB) adsorbed to the chemical composition of the adsorbent in the $\mathrm{Si} /(\mathrm{Al}+\mathrm{Fe})$ ratio, with adsorbents from the uncalcined (IA) and calcined (IB) soil dust samples, soil dust without the involvement of the DR1 (IIA), and soil samples (IIB). The sample used in the IA curve data is the same as that used in the IIA curve, except there are 2 samples that are not included in the IA because of the limited sample quantity (DPB and DPT samples). 

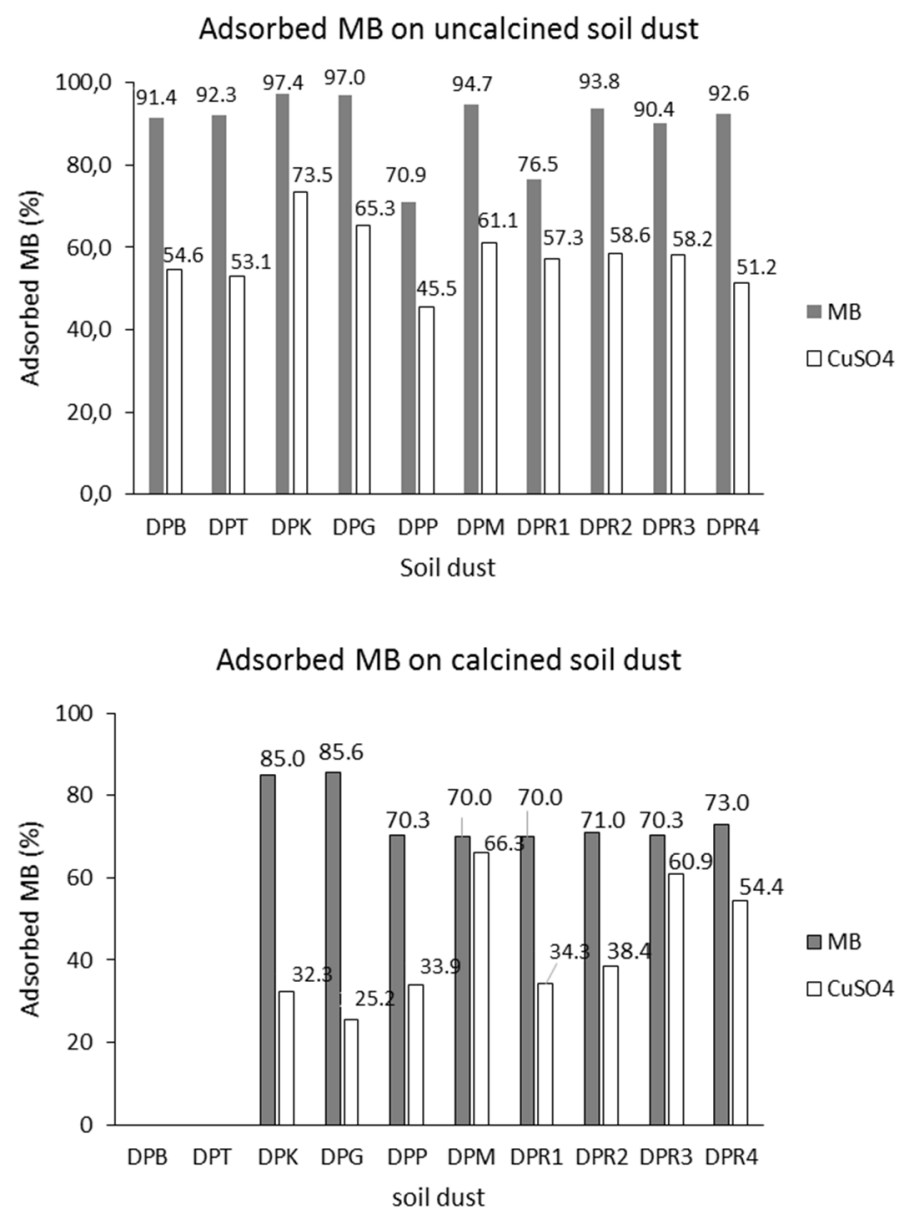

Figure. 3. Comparison of the percentage of $\mathrm{MB}$ with $\mathrm{CuSO}_{4}$ adsorbed, and both in calcined (above) and calcined (bottom) soil dusts. Trials on DPB and DPT samples were not carried out because the quantity was not sufficient as the other samples.

\subsection{The adsorption phenomenon of a colored solution of $\mathrm{CuSO}_{4}$}

We tried to examine the relationship of chemical composition of soil dust with adsorption power in inorganic colored substances, $\mathrm{CuSO}_{4}$ solutions. The solution of $\mathrm{CuSO}_{4}$ used was $20 \mathrm{~mL}$ with a concentration of $100 \mathrm{ppm}$, while the sample of soil dust used was 0.1 g. Using the same contact time in contact with the MB solution, soil dust adsorbed far less $\mathrm{CuSO}_{4}$ as shown in the comparison in Figure 3. However, in the case of contact with the $\mathrm{CuSO}_{4}$ solution we did not find the same adsorption pattern as what happened in MB based on data $R^{2}$, which is presented in Table 4 .

From Table 4 it can be seen that the presence of silicon element in calcined soil dust had a direct role in $\mathrm{CuSO}_{4}$ adsorption (Table 4, no. 1 to 6). Conversely, the remaining three 
elements, namely calcium, iron, and aluminum, have a greater influence on $\mathrm{CuSO}_{4}$ adsorption ability (Table 4, Figures 8 and 9). Increased correlation of adsorption power in samples of calcined soil dust was more likely to occur due to loss of organic matter, reducing hydrophobicity .

Table. $4 \mathrm{R}^{2}$ value of polynomial regression 2 between the percentage of adsorbed $\mathrm{CuSO}_{4}$ content and the quantity of chemical composition of soil dust.

\begin{tabular}{|c|c|c|c|}
\hline \multirow[t]{2}{*}{ No. } & \multirow[t]{2}{*}{$\begin{array}{l}\text { Statement } \\
\text { quantity } \\
\text { chemical } \\
\text { composition }\end{array}$} & \multicolumn{2}{|c|}{$\begin{array}{l}\text { The value of } \mathrm{R}^{2} \text { in the } \\
\text { polynomial } 2 \text { regression } \\
\text { of adsorbed } \mathrm{CuSO}_{4} \\
\text { against the quantity } \\
\text { statement of the chemical } \\
\text { composition of the } \\
\text { elements (in } \% \mathrm{w} / \mathrm{w})\end{array}$} \\
\hline & & $\begin{array}{c}\text { Without } \\
\text { calcination }\end{array}$ & $\begin{array}{c}\text { With } \\
\text { calcination }\end{array}$ \\
\hline 1 & $\mathrm{Si} / \mathrm{Al}$ & 0,4276 & 0,5217 \\
\hline 2 & Si-Al & 0,4441 & 0,5117 \\
\hline 3 & $\mathrm{Si} /(\mathrm{Al}+\mathrm{Fe})$ & 0,4016 & 0,4367 \\
\hline 4 & $(\mathrm{Si}-\mathrm{Al}) / \mathrm{Fe}$ & 0,4389 & 0,4195 \\
\hline 5 & $(\mathrm{Si}-\mathrm{Al}) / \mathrm{Ca}$ & 0,5595 & 0,6397 \\
\hline 6 & $(\mathrm{Si}-\mathrm{Al}) /(\mathrm{Fe}+\mathrm{Ca})$ & 0,2503 & 0,5362 \\
\hline 7 & $\mathrm{Ca}-\mathrm{Al}$ & 0,3299 & 0,4743 \\
\hline 8 & $(\mathrm{Ca}-\mathrm{Al}) / \mathrm{Fe}$ & 0,3477 & 0,7059 \\
\hline 9 & $(\mathrm{Ca}-\mathrm{Fe}) / \mathrm{Al}$ & 0,1602 & 0,7229 \\
\hline
\end{tabular}

Higher correlation of adsorption power without involving silicon because silica is more hydrophobic than calcium, iron and aluminum compounds. It is estimated that soil dust adsorbed less soluble compounds which have sufficient ionic bond characteristics such as $\mathrm{CuSO}_{4}$ because of the dominant silicon content in them. This estimate is in accordance with the comparison of the levels of $\mathrm{CuSO}_{4}$ with $\mathrm{MB}$ absorbed, both in soil dust without calcination and with calcination as shown in Figure 4.

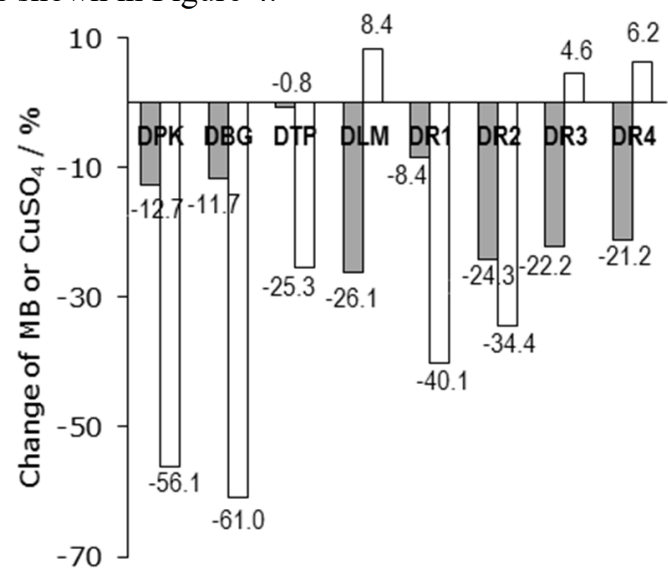

Figure. 4. Percentage of decrease or increase in $\mathrm{MB}$ (gray bar) and $\mathrm{CuSO}_{4}$ (white bar) weight after soil dust samples were calcined. 
It can be seen that $\mathrm{MB}$ and $\mathrm{CuSO}_{4}$ adsorbed by uncalcined soil dust are generally more than calcined soil dust. This can be explained because the amount of uncalcined soil dust still contains organic matter as a result of the anthropogenic and natural interactions of the soil as part of the carbon cycle. The presence of these organic substances causes more adsorption of $\mathrm{CuSO}_{4}$ and $\mathrm{MB}$ in uncalcined soil dust than calcined so that it can be predicted the adsorption of $\mathrm{CuSO}_{4}$ on substances in soil dust through covalent coordinate interactions between $\mathrm{Cu}^{2+}$ and atoms of free electron pairs from these organic materials. Meanwhile, MB adsorption is estimated through polar-polar covalent interactions between groups $\mathrm{R}=\mathrm{N}^{+}\left(\mathrm{CH}_{3}\right)_{2}$ with polar, or non-polar - non-polar interactions between $\mathrm{R}-\mathrm{N}\left(\mathrm{CH}_{3}\right)_{2}$ groups and non-polar groups of organic substances of soil dust.

\subsection{Calcination effect on decreasing the percentage of $\mathrm{MB}$ and $\mathrm{CuSO}_{4}$ levels}

From the list of coefficient of determination (Tables 3 and 4), the form of non-linear regression curves (Figure 2), and the percentage of MB adsorbed (Figure 3), it can be seen that the calcination treatment affected a significant change in the adsorption pattern. Changes that occur are easier to see by comparing samples that were not calcined with calcined soils which tend to follow open downward and upward parabolic equations, respectively (Figure 2, IA and IB). Based on the literature, the content of organic matter in soil and soil dust only ranges up to around 5\% [3] [58], the range of this percentage is much smaller when compared to most of the adsorption percentage of $\mathrm{MB}$ and $\mathrm{CuSO}_{4}$ as shown in Figure 4.

However, analogous research with the interaction of organic substances in soil minerals containing organic substances is still difficult to find. The only results found came from Shen (1999) which showed that the content of soil materials tended to inhibit the adsorption of dissolved organic matter [42], in contrast to our results using variations in soil dust samples (Figure 4). Based on Figure 4, it can be obtained the fact that the organic matter contained in soil dust has a large role for most samples of soil dust in adsorbing $\mathrm{MB}$ and $\mathrm{CuSO}_{4}$. A significant difference occurred in $\mathrm{CuSO}_{4}$ adsorption because in DPK, DBG, DPP, DR1, and DR2 samples there was a decrease in the percentage of adsorption in the range of 25.34 $60.98 \%$ after the samples were calcined, exceeding the decrease in MB level in that range, $0.79-26.09 \%$. Another difference, MB adsorption decreased in all samples, while in $\mathrm{CuSO}_{4}$ three samples actually increased after calcined soil dust samples, namely DLM, DR3, and DR4.

\subsection{Comparison of MB adsorption in soil dust, soil, and building wall dust}

Based on the results of contact with the $\mathrm{MB}$ and $\mathrm{CuSO}_{4}$ solutions with soil or soil dust in Figure 3, it can be seen that the compounds of the main elements of the soil content are more effective in absorbing $\mathrm{MB}$ than $\mathrm{CuSO}_{4}$. From this phenomenon it can be predicted that the tendency of more MB to be adsorbed is due to the dominant tendency of hydrophobichydrophobic interactions. $\mathrm{MB}$ is more hydrophobic than $\mathrm{CuSO}_{4}$, whereas soil or soil dust content tends to be dominated by silica and aluminosilicate which tend to be more hydrophobic than calcium and iron oxide. The percentage of high adsorbed MB is similar to that occurring in three building wall dust samples as presented in Table 5. 
Table 1. Comparison of the percentage of MB adsorbed by soil dust, soil, and building wall dust during contact time for 2 minutes.

\begin{tabular}{lcl}
\hline $\begin{array}{l}\text { Sample } \\
\text { code }\end{array}$ & $\begin{array}{l}\text { Percentage of } \\
\text { adsorbed MB }\end{array}$ & $\begin{array}{l}\text { General description } \\
\text { of adsorption power }\end{array}$ \\
\hline \multicolumn{3}{c}{ Adsorption on soil dust sample ${ }^{1}$} \\
DPB & 91.40 & \\
DPT & 92.29 & \\
DRP & 97.37 & \\
DBG & 97.00 & range $=$ \\
DTP & 70.90 & $70.90-97.37 \%$ \\
DLM & 94.74 & average $=$ \\
DR1 & 76.46 & $89.69 \%$ \\
DR2 & 93.78 & \\
DR3 & 90.37 & \\
DR4 & 92.62 & \\
\hline
\end{tabular}

\begin{tabular}{lcl}
\hline \multicolumn{3}{l}{ Adsorption on soil sample ${ }^{2}$} \\
TK1 & 99.75 & \\
TK2 & 60.01 & range $=$ \\
TG1 & 61.54 & $60.01-99.75 \%$ \\
TG2 & 69.88 & average $=$ \\
TI1 & 92.08 & $80.45 \%$ \\
TI2 & 99.42 & \\
\hline Adsorption on building wall dust & \\
DDK & 89.50 & range $=$ \\
DDP & 96.77 & $89.50-92.93 \%$ \\
DDB & 92.53 & average $=92.93 \%$ \\
\hline
\end{tabular}

${ }^{1}$ Soil dust samples were obtained from under the house on stilts (DRP) and soil dust from house construction (DBG) from Mande Sub-District, Cianjur Regency, dust from the ground of a bus vehicle in the inter-city bus terminal Leuwi Panjang, Bandung (DPB), a vehicle parking lot in the yard of one of the mosques in Cirebon City (DTP), the dust floor of a mosque in one of the mosques in Cikampek SubDistrict, Karawang Regency (DLM), floor dust from a textile factory in Cimahi City (DPT), dust from a floor mat from one of the houses in Cinunuk Sub-District, Bandung Regency (DR1), one sample of dust from the house floor where DR1 (DR2) was made a sample, and two samples of house floor dust from Cikampek Sub-District,, Karawang Regency (DR3 and DR4).

${ }^{2}$ Soil samples were obtained from around the boundaries of the administrative region of Sumedang Regency and Bandung Regency, namely from tobacco plantations owned by residents in Cinanjung Village, Tanjungsari Sub-District (TK1), corn plantations in Sukawangi Village, Pamulihan Sub-District (TK2), the slopes of Mount Geulis, Jatiroke Village, Jatinangor Sub-District, Sumedang Regency (TG1), the slopes of Mount Manglayang, Cibacang Sub-Village, Sindangsari Village, Sukasari Sub-District 
(TG2), and two of the industrial zones in Rancaekek Sub-District, Bandung Regency, which are close to garment factories (TI1) and residential population (TI2).

${ }^{3}$ Building wall dust samples were obtained by mixing homogeneously and equal weight ratios from several building locations to represent a coded sample, with building types consisting of residential houses, school buildings, or village offices in calcareous hilly areas in Tamansari Village, Pangkalan Sub-District, Purwakarta Regency (DDK), a coastal area around the border of Karawang Regency with Subang Regency (DDP), and the Cimumput Hill area, Jatiluhur Sub-District, Purwakarta Regency (DDB).

Among soil dust, there was a very different percentage of adsorption power seen in dust samples from vehicle parking lots (DTP) and house doormats (DR1), whereas in soil samples this striking difference was seen in hill soil samples (TG1 and TG2). Although the sample of building wall dust adsorbs MB quite high, its representation cannot be ascertained because it only involved a small number of samples (three samples). However, with the results of the adsorption experiments as shown in Tables 3, 4 and 5, it can be predicted that soil dust has similarities with variations in soil adsorption ability against $\mathrm{MB}$, which is related to the composition of four main elements. Although not enough to represent the number and variety of samples, the ability of building wall dust to adsorb MB is still related to the content of the main elements, namely $\mathrm{Si}, \mathrm{Al}, \mathrm{Fe}$, and $\mathrm{Ca}$, as shown in Figure 5.
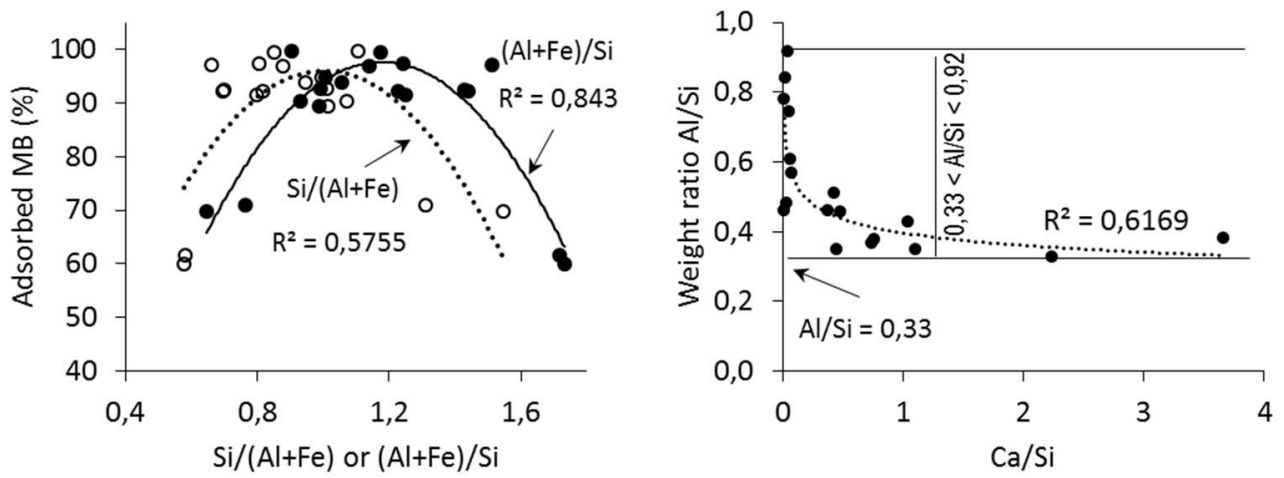

Figure. 5. Comparison of $\mathrm{R}^{2}$ values in the polynomial 2 regression correlation between the percentage of MB adsorbed to the statement of levels of 3 elements of soil dust content, soil, and dust of building walls ( $\mathrm{Si}, \mathrm{Al}$, and $\mathrm{Fe}$ ) (left) and the relationship between the ratio of $\mathrm{Al} / \mathrm{Si}$ levels to $\mathrm{Ca} / \mathrm{Si}$ (right).

In Figure 5, it can be seen that the statement of level $(\mathrm{Al}+\mathrm{Fe}) / \mathrm{Si}$ is more precise than $\mathrm{Si} /(\mathrm{Al}+\mathrm{Fe})$ for the effect on the MB level absorbed by the soil, soil, and wall dust. It can be seen that the element $\mathrm{Ca}$ did not have a direct effect on the adsorption power of the three types of material, but precisely the presence of $\mathrm{Ca}$ directly affects the content of $\mathrm{Al}$. Based on the plot of $\mathrm{Al} / \mathrm{Si}$ against $\mathrm{Ca} / \mathrm{Si}$, it can be seen that the increase in Ca levels in samples of soil dust, soil, and building wall dust, were in line with a decrease in Al levels in a non-linear manner. This phenomenon can be understood because $\mathrm{Ca}$ and $\mathrm{Al}$ have the character to compete in contributing to the adsorption properties of materials [59]. The presence of calcium salts, especially $\mathrm{CaCO}_{3}$ will increase soil $\mathrm{pH}$ and dissolved $\mathrm{Al}$ levels [60]. This property will produce hydroxy complexes from soluble aluminum, such as $\mathrm{Al}(\mathrm{OH})_{2}^{+}, \mathrm{Al}(\mathrm{OH})^{2+}$, and $\mathrm{Al}(\mathrm{OH})_{4}^{-}[61]$. 
We found that the range of the $\mathrm{Al} / \mathrm{Si}$ content ratio was around 0.33 to 0.92 . From Figure 5 (below) it can be seen that a slight increase in Ca content coincided with a drastic decrease in the level of $\mathrm{Al}$, while a further increase in the level of $\mathrm{Ca}$ did not affect the level of $\mathrm{Al}$ until the $\mathrm{Al} / \mathrm{Si}$ ratio was around 0.33 . Based on the results of the $\mathrm{Ca} / \mathrm{Si}$ ratio, the ratio of $\mathrm{Ca} / \mathrm{Si}$ levels more than 0.4 tends to have anthropogenic activity characteristics, such as house floor dust (DR2, DR3, and DR4), vehicle parking dust (DTP) and interior public bus dust (DPB), mosque floor dust (DLM), garment factory floor dust (DPT), and building wall dust (DDK, $\mathrm{DDB}$, and DPP). While the ratio of $\mathrm{Ca} / \mathrm{Si}$ levels less than 0.4 had more natural properties, such as soil samples (TK1, TK2, TG1, TG2, TI1, and TI2), soil dust from former excavated soil (DBG), and soil dust from under the stilt house (DRP). Thus, the presence of calcium elements did not have a direct contribution to the adsorption of organic matter, similar to that obtained by Mikutta et al., but we found a new fact that its abundance affects the level of $\mathrm{Al}$ in the dust of the soil, the soil, and the dust of the building walls.

\subsection{The phenomenon of grouping the types of interactions on MB and CuSO4 adsorption by calcined soil dust}

According to Figure 4, it can be generally seen that calcination has the effect of reducing adsorption power, so that organic matter in soil dust has a significant role in adsorption power. In the soil, the presence of aluminum oxide is not in the form of a single aluminum oxide (such as $\mathrm{Al}_{2} \mathrm{O}_{3}$ ), but as an aluminosilicate geopolymer, while $\mathrm{Si}$ and $\mathrm{Ca}$ oxides can stand alone (such as $\mathrm{SiO}_{2}$ and $\mathrm{CaO}$ ) or combine as calcium aluminosilicate. Iron oxide can have a tendency to stand alone as $\mathrm{Fe}_{2} \mathrm{O}_{3}$ or $\mathrm{Fe}_{3} \mathrm{O}_{4}$. However, based on phase determination using Xray diffraction (Figure 1), it is likely that most iron was present in the soil dust sample as a combination of aluminosilicate compounds due to the lack of detection of iron oxides such as $\mathrm{FeO}, \mathrm{Fe}_{2} \mathrm{O}_{3}$, or $\mathrm{Fe}_{3} \mathrm{O}_{4}$. In both the single oxide form and in combination with aluminosilicate, the role of this iron has been known to increase soil adsorption power against MB [62], improve the stability of other organic substances in the soil [44], and which have a role in the catalytic decomposition of soil organic matter [63].

Furthermore, we look at the grouping characteristics of $\mathrm{MB}$ and $\mathrm{CuSO}_{4}$ adsorption which are affected by changes in $\mathrm{Si}-\mathrm{Al}$ and $\mathrm{Fe}-\mathrm{Ca}$ differences from soil dust as shown in Figure 6. From the percentage of $\mathrm{MB}$ or $\mathrm{CuSO}_{4}$ adsorbed, an increase in $\mathrm{Si}$ content reduced the adsorbed MB level but increasing the level of adsorbed $\mathrm{CuSO}_{4}$, and vice versa for the increase and decrease in Al level. The opposite phenomenon occured in differences in the increase and decrease in $\mathrm{Fe}$ and $\mathrm{Ca}$ levels. With this phenomenon, the interaction of $\mathrm{MB}$ and $\mathrm{CuSO}_{4}$ with soil dust particles can be proposed to occur as shown in Figures 7 and 8 . 

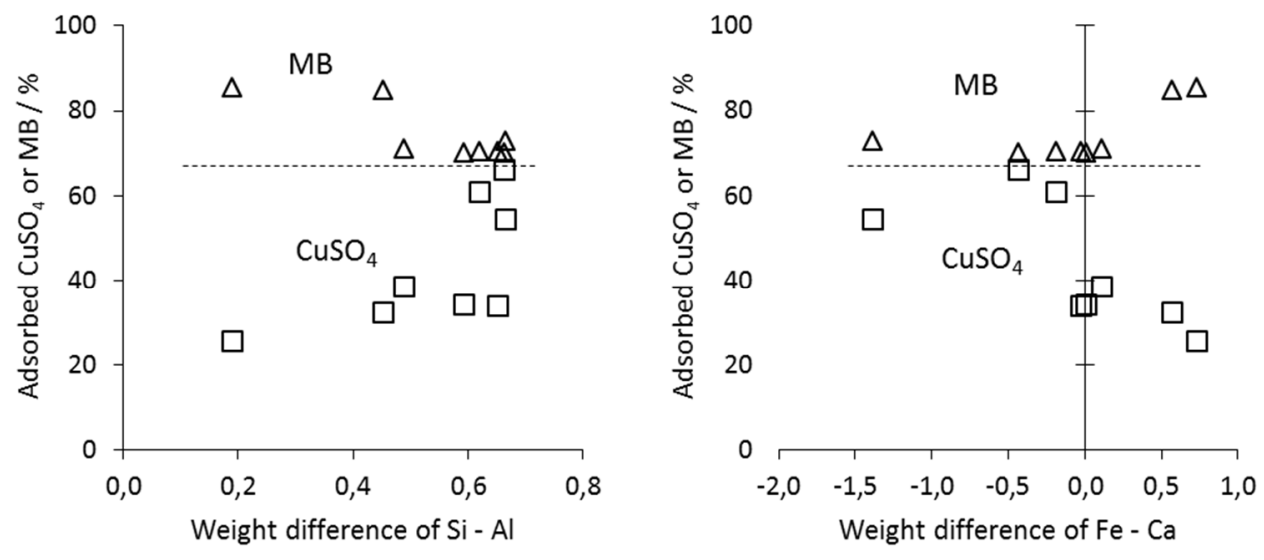

Figure. 6 The phenomenon of the percentage of $\mathrm{MB}$ and $\mathrm{CuSO} 4$ adsorbed by calcined soil dust results in a grouping pattern based on the difference in levels of $\mathrm{Si}-\mathrm{Al}$ with $\mathrm{Fe}-\mathrm{Ca}$.

Based on the references in this study, there are several types of proposed interactions between MB and soil dust particles, namely $\mathrm{Al}$ and Fe covalently coordinated [41] [43] [44], Si non-polar covalent [42], and Ca acts as a bridge cation [45] between MB molecules through the donor electron lone atom ( $\mathrm{N}$ or $\mathrm{S})$. Thus, it can be understood that the adsorption of organic molecules by soil and soil dust represents all types of adsorption, physisorption represented by the presence of $\mathrm{Si}$ element and chemisorption by $\mathrm{Ca}, \mathrm{Al}$, and $\mathrm{Fe}$ elements.

From the explanation above, the behavior of $\mathrm{MB}$ and $\mathrm{CuSO}_{4}$ adsorbed by soil dust particles were estimated from a range of two types of interactions, namely hydrophobichydrophilic in a combination of bonds involving $\mathrm{Si}$ and $\mathrm{Al}$ elements, ionic or covalent, and covalent coordinates involving $\mathrm{Fe}$ and $\mathrm{Ca}$ oxides. Furthermore, $\mathrm{MB}$ as a more hydrophobic spesies than $\mathrm{Cu}^{2+}$ and $\mathrm{SO}_{4}^{2-}$ ions was predicted to interact more strongly with aluminosilicate geopolymers (Figure 7), whereas $\mathrm{Cu}^{2+}$ and $\mathrm{SO}_{4}^{2-}$ tend to interact with iron and calcium compounds (Figure 8). 
<smiles>CCOCCOC</smiles><smiles>[R][N+](C)(C)C</smiles>

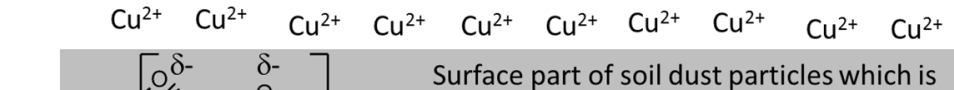<smiles>[CH2-][NH2+]C</smiles><smiles>C[NH2+]C</smiles>
negatively charged or partially negative, $\delta$ -

Soil dust particle that was calcined

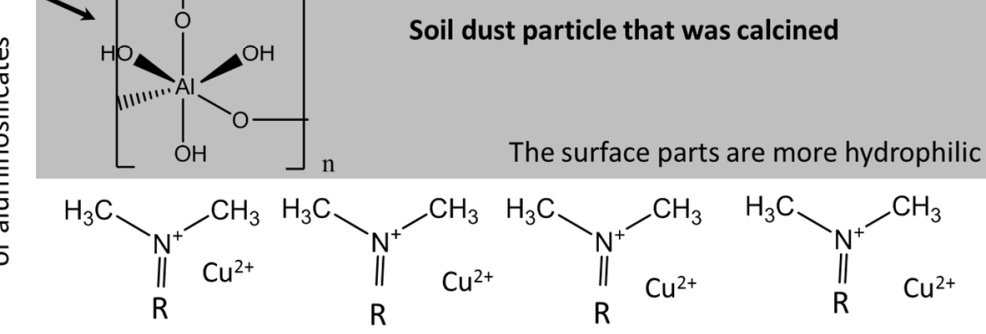

$R=$ The part of functional group of the MB structure that interacts with soil dust particles

Figure. 7 The proposed description for the interaction of soil dust particles without organic matter (calcined soil dust) with $\mathrm{MB}$ was compared with $\mathrm{Cu}^{2+}$ for the effect of levels of $\mathrm{Si}$ and $\mathrm{Al}$ elements derived from a combination of the presence of silica, silicate, or aluminosilicate.

As shown in Figures 7 and 8, the ability of soil dust to adsorb $\mathrm{MB}$ and $\mathrm{CuSO}_{4}$ can be understood based on the presence of solid compounds containing four main elements of soil dust content, namely $\mathrm{Si}, \mathrm{Al}, \mathrm{Fe}$, and $\mathrm{Ca}$. However, the higher percentage of $\mathrm{MB}$ that can be adsorbed was not only determined by the four main elements, but also the organic matter present in the soil dust sample because after calcination it will reduce its adsorption power to MB rather than $\mathrm{CuSO}_{4}$. After samples of soil dust were removed from organic matter (via calcination), the highest tendency for adsorption remained in the DRP and DBG samples. In addition, there is prediction that the levels of $\mathrm{Al}$ and $\mathrm{Fe}$ have a greater effect than $\mathrm{Ca}$ in adsorbing MB. DR4 and DLM samples are two samples that have the highest Ca content, even Ca levels exceed Si levels, but both are not the highest adsorption samples. In fact, after organic matter was removed through calcination, the two samples included samples that had the lowest MB adsorption (Figure 3). Thus, differences in Si-Al levels and increased Fe levels were the main causes of increased MB adsorption. 
More basic condition

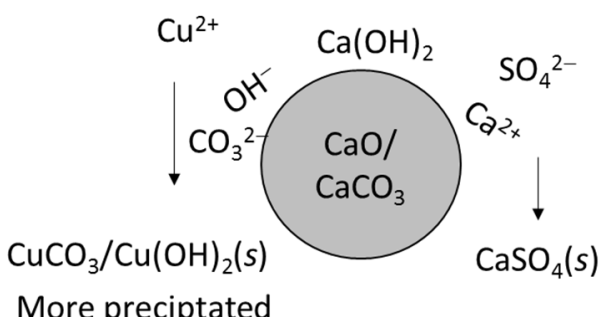

Less basic condition

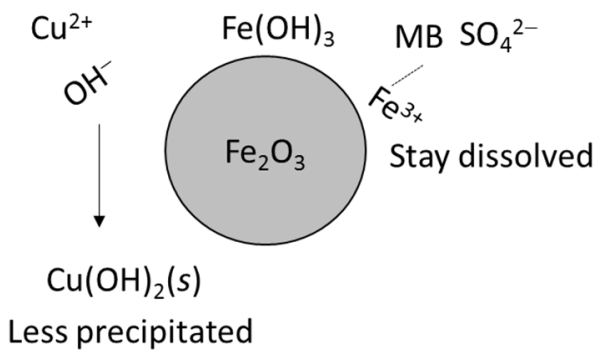

Figure. 8 The proposed description for the interaction of calcium oxide/carbonate particles and iron oxide in soil dust with $\mathrm{Cu}^{2+}$ and $\mathrm{SO}_{4}^{2-}$ ions.

Uncalcined DBG and DTP each gave the highest and lowest adsorption power to MB (Figure 3, above), but into two samples which had the lowest reduction in adsorption power after calcination (Figure 4). DBG and DTP were two samples that had the highest and lowest $\mathrm{Fe}-\mathrm{Ca}$ values (Figure 6). This was followed by the highest and lowest Al levels (Table 2). From this phenomenon it can be seen that the increase in $\mathrm{Al}$ and Fe levels in calcined soil dust increases $\mathrm{MB}$ adsorption but decreases the adsorption of $\mathrm{CuSO}_{4}$, whereas an increase in the levels of $\mathrm{Si}$ and $\mathrm{Ca}$ had the opposite effect.

According to Figure 7, the chemical effect of $\mathrm{Al}$ on $\mathrm{MB}$ adsorption is the polarity of the $-\mathrm{Al}-\mathrm{OH}$ bonding of aluminsolicates with positive charge side $-\mathrm{R}=\mathrm{N}^{+}-\left(\mathrm{CH}_{3}\right)_{2}$ of $\mathrm{MB}$, the effect of $\mathrm{Fe}$ is caused by the interaction of coordinate covalent bond between Fe and $\mathrm{MB}$ through one electronegative atoms, $\mathrm{S}$ or $\mathrm{N}$ that are not charged, or both. Meanwhile, reduced levels of $\mathrm{CuSO}_{4}$ are estimated through the physisorption mechanism between $\mathrm{Cu}^{2+}$ ions and negative partial charge from the $\equiv \mathrm{T}-\mathrm{O}-\mathrm{T} \equiv$ framework, and chemisorption via precipitation reaction that produce $\mathrm{CuCO}_{2}, \mathrm{Cu}(\mathrm{OH})_{2}$, or $\mathrm{CaSO}_{4}$. With this explanation, soil dust particles can remove $\mathrm{MB}$ and $\mathrm{CuSO}_{4}$ from solutions through various modes of interaction, physical phenomena (interaction of charge, partial charge, and polarity) and chemisorption (complex formation and precipitation reaction).

\subsection{Adsorption isotherm model, surface area, and pore}

The high adsorption power of soil dust to $\mathrm{MB}$ is interesting to explore further the adsorption model compared to $\mathrm{CuSO}_{4}$, because it can be ascertained its interaction with $\mathrm{CuSO}_{4}$ with soil dust particles also through the precipitation reaction mechanism. After the adsorption isotherm test, MB tend to be adsorbed following the Freundlich model with a reasonably good $R^{2}$ in the sample without calcined $\left(R^{2}=0.9885\right)$ or calcined $\left(R^{2}=0.9796\right)$ (Figure 9). The Langmuir model is not displayed because it has an unfavorable $\mathrm{R}^{2}$ value, $\mathrm{R}^{2}$ $<0.95$. The Freundlich model is more suitable according to the results obtained by previous researchers using hydrophobic organic compounds in the soil [64] [65] and silica [66].

With $\mathrm{R}^{2}$ obtained in the Freundlich isotherm adsorption model (Figure 9), uncalcined soil dust and calcined soil dust adsorb multi-layered MB, occur on heterogeneous surfaces, and active sites have different amounts of energy. This phenomenon is in line with the role of the four main elements which are considered to have a direct influence on various active sites of MB adsorption on soil dust. In addition to the Freundlich and Langmuir models, adsorption 
isotherm data was also tested using linear or non-linear regression for the BET adsorption model, using plots $\frac{\mathrm{Ce} / \mathrm{Co}}{Q e(1-\mathrm{Ce} / \mathrm{Co})}$ against $\frac{\mathrm{Ce}}{\mathrm{Co}}$ ( $\mathrm{Co}=$ initial concentration of adsorbate). BET regression test results showed that the uncalcined soil dust samples produced linear regression with $\mathrm{R}^{2}=0.990$, while the calcined soil dust samples as exponential regression with $\mathrm{R}^{2}=$ 0.995. With a high linearity perspective in this BET isotherm regression, the MB adsorption interaction model on the surface of this soil dust particle (not calcined and calcined) has not yet determined the adsorption model, Freundlich or Langmuir.

Although in the case of this study testing the isotherm adsorption model leading to the conclusion is more suitable as Freundlich adsorption, testing the BET isotherm adsorption model shows two different regression forms, linear and nonlinear (exponential). Based on the literature, there are many isotherm adsorption models, but most of the models derived from Freundlich, Langmuir, or a combination of both models, except BET [67]. However, the BET model can be erroneous and ambiguous for isothermic adsorption systems involving adsorbate in the liquid phase [67] [68]. Thus, in this study the BET adsorption model has not been able to distinguish the interaction of MB-soil dust as a multilayer or single layer.
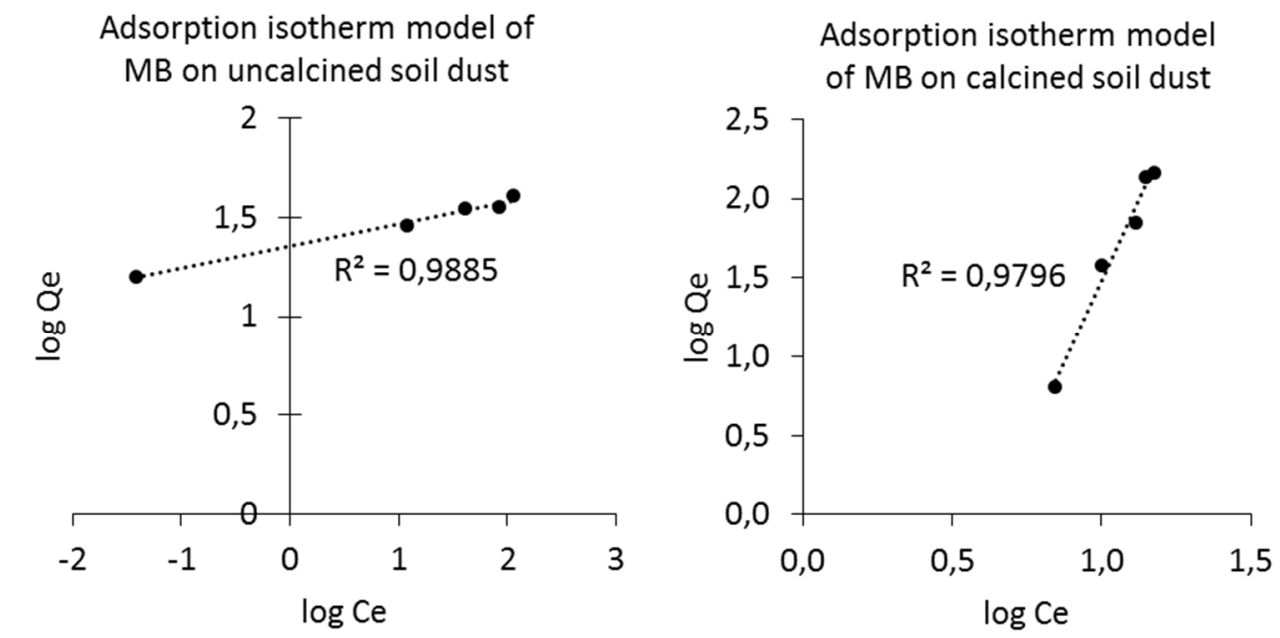

Figure. 9. Linear regression of the Freundlich MB isotherm adsorption model in calcined soil dust (left) and calcined soil dust (right), with Qe representing the adsorbate mass adsorbed per mass of adsorbent at equilibrium $(\mathrm{mg} / \mathrm{g})$ and $\mathrm{Ce}$ as the concentration of adsorbate solution at equilibrium.

Although the BET adsorption model cannot distinguish the adsorption model, the BET adsorption model in this study can still be used in surface area prediction, through BET adsorption-desorption curve data using $\mathrm{N}_{2}$ gas (Figure 10). The samples tested consisted of three samples that had the highest adsorption power representation, namely uncalcined soil dust (represented by DRP sample), calcined soil dust (represented by calcined DBG sample), and soil (represented by TK1). The specific surface area $\left(\mathrm{S}_{\mathrm{BET}}\right)$ of the three can be predicted from the following linear equation [69], 


$$
\frac{1}{V_{a}\left\{\left(\frac{P}{P_{0}}\right)-1\right\}}=\frac{1}{V_{m} \cdot C}+\frac{C-1}{V_{m} \cdot C}\left(\frac{P}{P_{0}}\right) ; S_{B E T}=\frac{V_{m} \cdot N \cdot a}{m \cdot 22400}
$$

where $\mathrm{Va}=$ the volume of adsorbed gas, $\mathrm{P}=$ partial vapor pressure of the adsorbate in equilibrium with the surface of the adsorbate at $77.4 \mathrm{~K}, \mathrm{P0}=$ saturated pressure of the adsorbate gas, $\mathrm{Vm}=$ the volume of gas adsorbed at temperature and standard pressure to produce a single layer on the surface adsorbent, calculated by $1 /($ slope+intercept), $\mathrm{C}=$ dimensionless constant related to the enthalpy of adsorption from adsorbate gas on adsorbent powder, calculated by (slope/intercept) $+1, \mathrm{~N}=$ Avogadro number, $\mathrm{a}=$ effective cross-sectional area of one adsorbate molecule, $\mathrm{m}=$ mass of adsorbent powder (in g), and $22400=$ volume occupied by one adsorbate gas molecule at standard temperature and pressure. By using the data used to make the curve in Figure 10, the tabulation and the results of the calculation of the surface area of soil dust are obtained in Table 6 .

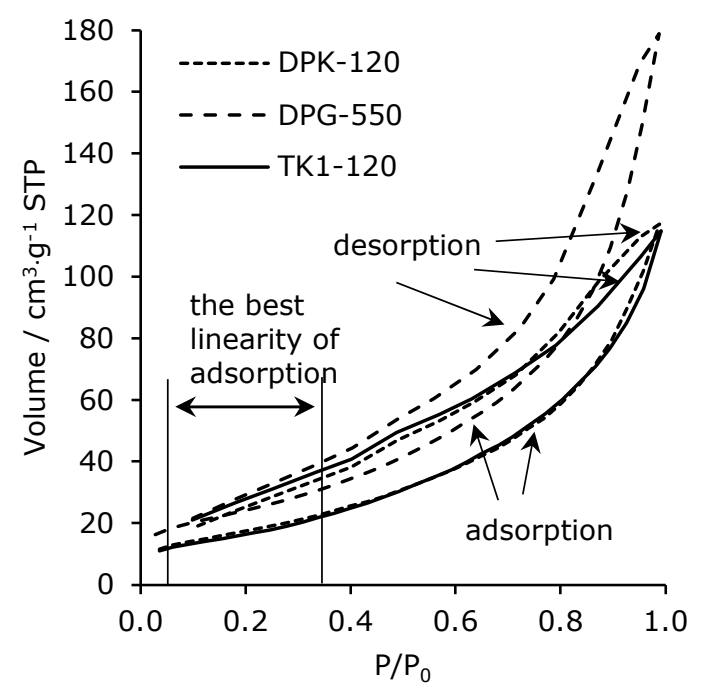

Figure. 10. The BET isotherm adsorption desorption model uses $\mathrm{N}_{2}$ adsorbate from soil dust samples from the stilt house (DPK), calcined soil dust (DPG), and garden soil (TK1)

As seen in Figure 10 there are differences in the characteristics of the pore volume along with the increasing and decreasing of pressure. Excavated soil and garden soil samples (both not calcined) did not have a significant difference in volume per gram, while calcined soil dust sample (DBG-550) increased their ability to adsorb. Unlike most other material cases, the largest pore volumes based on the size of the diameter of the pore in soil and soil dust samples actually dominate and tend not to change even though the diameter of the pore increases from about 40 to more than $100 \mathrm{~nm}$ as shown in Figure 11. 


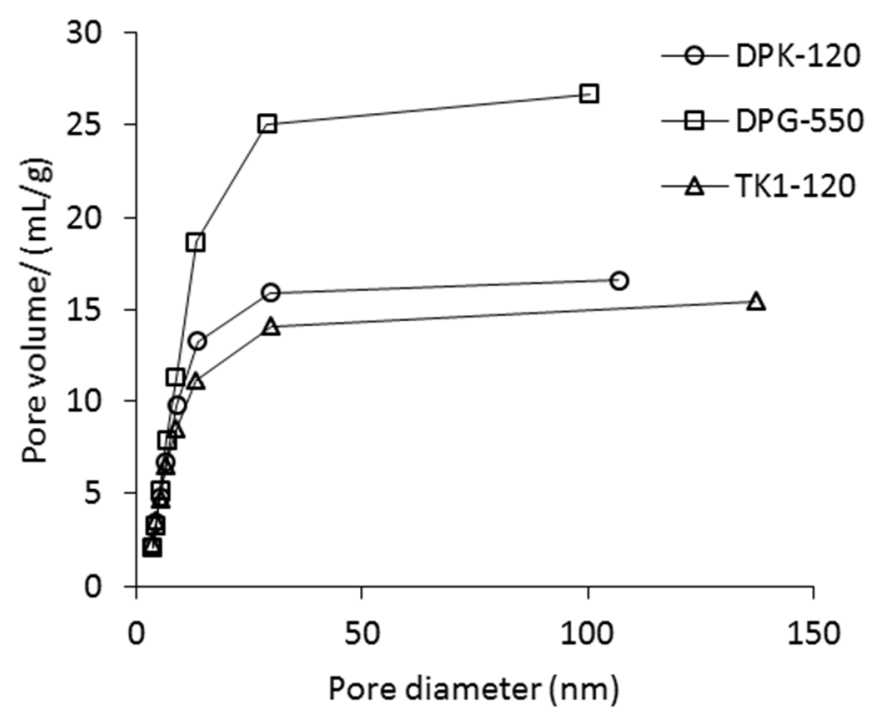

Figure. 11 Comparison of pore size distribution of samples that have the highest adsorption power in uncalcined soil dust (DPK-120), calcined soil dust (DPG-550), and soil powder (TK1-120).

Table. 5 Tabulation of calculation results and comparison of surface area of soil dust samples that have the highest adsorption power in soil samples that are not calcined and calcined, as well as in soil samples.

\begin{tabular}{|c|c|c|}
\hline Sample $^{1}$ & Data $\mathrm{P} / \mathrm{Po}^{2}$ & $\mathrm{~S}_{\mathrm{BET}} / \mathrm{m}^{2} \cdot \mathrm{g}^{-13}$ \\
\hline DPK-120 & $0,0378-0,3045$ & 65,701 \\
\hline DPG-550 & $0,0279-0,3036$ & 89,026 \\
\hline TK1-120 & $0,0359-0,3094$ & 62,229 \\
\hline
\end{tabular}

${ }^{1} 120$ code represents only dried samples at $120{ }^{\circ} \mathrm{C}$, and 550 represents samples calcined at $550{ }^{\circ} \mathrm{C} ;{ }^{2} \mathrm{The}$ $\mathrm{P} / \mathrm{P}_{0}$ data was taken from the $\mathrm{P} / \mathrm{P}_{0}$ values that have the best linearity based on the $\mathrm{R}$ value, ${ }^{3}$ the surface area calculation used the value of $a$ gas $\mathrm{N}_{2}=16.2 \AA^{2}$.

As shown in Figure 11, the BJH (Barret-Joyner-Hallenda) adsorption method, dust soil and soil particles do not seem to have a maximum limit on the diameter of their pores. This situation shows that the particle pore diameter description cannot be understood assuming that the channel have a cross-section shapes or close to circles, but most parts are spaces between clay mineral sheets that can expand or shrink. This characteristic can be predicted to arise from clay structures which are generally piles of polymer sheets. Said to be a polymer because clay minerals are categorized as geopolymers. Geopolymers themselves are abundant in the earth's crust, derived from silicate and aluminosilicate compounds [70].

Calcined soil dust samples represent soil dust or soil without the presence of humus or other organic materials resulting from weathering living things that have died, the process of interaction with microorganisms, or anthropogenic interactions. The organic matter contained 
in soil dust fills the clay mineral polymer sheets so that the $\mathrm{N}_{2}$ adsorption isotherm did not change much in volume (Figure 11). This happened because inter-polymer sheets can be chemically connected through organic molecules with various functional groups [3]. With a larger pore volume than an uncalcined sample, it is clear that organic matter in soil dust had a direct influence on the stiffness or flexibility of the dimension of pore volume or soil dust. The peculiarities of soil minerals can naturally bind organic molecules and between organic substances can be bound to each other so that more organic matter can be adsorbed by soil dust particles through interactions between functional groups and appropriate physical interactions. This is consistent with the predicted isotherm adsorption model, which is more compatible with the Freundlich model than Langmuir.

From the overall presentation of the results and discussion of this study we obtained a fairly complete picture that the ability of soil dust to adsorb $\mathrm{MB}$ and $\mathrm{CuSO}_{4}$ in the solution medium has a close relationship with the content of its main elements, $\mathrm{Si}, \mathrm{Al}, \mathrm{Fe}$, and $\mathrm{Ca}$. The content of organic matter has a relationship with the level of four elements and generally increases the adsorption ability of $\mathrm{MB}$ and $\mathrm{CuSO}_{4}$, except for a small number of cases (three out of eight of soil dust samples) which reduce $\mathrm{CuSO}_{4}$ adsorbed. This type of interaction is not simple, but is a mixture of physisorption and chemisorption, as well as fairly complete interactions including covalent, ionic, and coordinate covalent interactions. The complexity of the interaction model has been shown in Figures 7 and 8, and can be summarized more fully in Figure 12. From Figure 12 it can be seen that soil dust has many alternative interactions to be able to adsorb chemical species with wide physical and chemical characteristics.

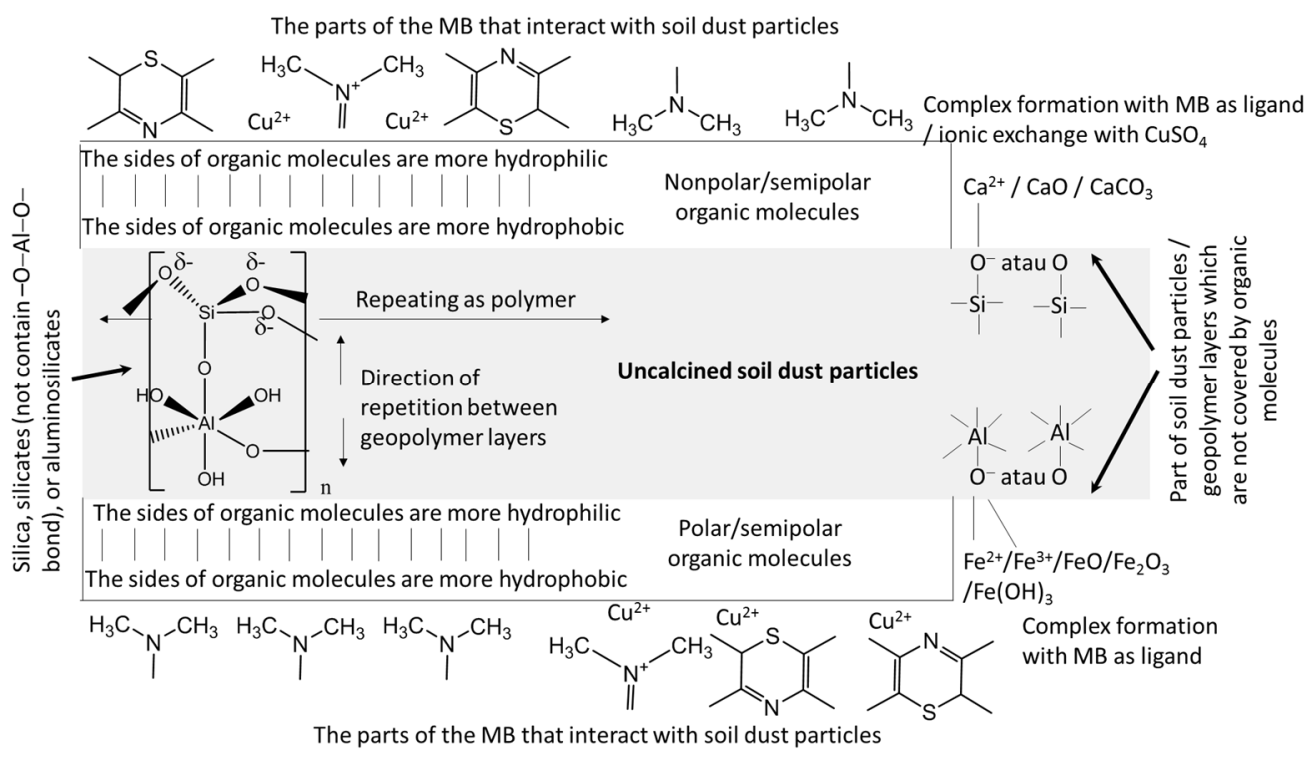

Figure. 12. An overview of the proposed interactions regarding the ability of soil dust particles (containing organic substances) to adsorb $\mathrm{MB}$ and $\mathrm{CuSO}_{4}$. 


\subsection{Explanation of the results of experiments and literature studies in understanding the practice of ritual purification using soil dust}

In Islam teachings, the practice of ritual purification involves the cleansing of limbs or containers exposed to unclean objects. The only practice of ritual purification that using dust soil is tayamum, while using water is ablution. However, generally purifying unclean/najis and other impurities using only water, soil dust, or both. The use of both can be understood because they have cleansing power against najis and impurity, but with different molecular mechanisms.

If we associate with unclean chemical composition and types of impurities, the use of water is more considered on cleaning objects that have hydrophilic properties so that unclean substances and impurities can be dissolved and can be rinsed easily, whereas with soil dust having lower solubility or less hydrophilic. The analogy of the mechanism of soil dust as an effective adsorbent is in principle the same as the $\mathrm{MB}$ and $\mathrm{CuSO}_{4}$ adsorption mechanism proposed from this study, as shown in Figure 12. If related to taharah (purification), furthermore, soil dust is more effective in adsorbing organic matter than inorganic ions. This shows the effectiveness of soil dust in cleaning unclean substances because the unclean substances themselves are dominated by organic substances, while the inorganic ions that accompany them are more easily rinsed with water.

If we associate with chemical composition of unclean substances and types of impurities, the use of water is more considered on cleaning objects that have hydrophilic properties so that unclean substances and impurities can be dissolved and can be rinsed easily, whereas with soil dust having lower solubility or less hydrophilic. The analogy of the mechanism of soil dust as an effective adsorbent is in principle the same as the $\mathrm{MB}$ and $\mathrm{CuSO}_{4}$ adsorption mechanism proposed from this study as shown in Figure 12. If related to taharah (purification), furthermore, soil dust is more effective in adsorbing organic matter than inorganic ions. This shows the effectiveness of soil dust in cleaning unclean substances because the unclean substances themselves are dominated by organic substances, while the inorganic ions that accompany them are more easily rinsed with water.

One of the facts in this research is the small adsorption power of soil dust from the door mat (DR1) and the parking lot (DTP), so both of them are representations of the most unsuitable soil dust for purification. The DR1 sample is estimated to be the most saturated with anthropogenic organic matter compared to other samples. While the DTP sample has lost a lot of its adsorption power, the calcination treatment did not give a change in the levels of Si, $\mathrm{Al}, \mathrm{Fe}$, and $\mathrm{Ca}$ (Table 2, row 5). The small adsorption power of the DTP sample is estimated due to the dominant phase of the albit which is an aluminosilicate mineral with very low porosity, adjacent to the quartz porosity as discussed earlier (section 3.1).

The size of soil dust particles is finer than soil particles that are dug directly from the soil. As for the soil, it still has adsorption properties of organic substances that are effective if made into fine particles, in accordance with the understanding of adsorption kinetics, namely a wider surface, so that the active sites are more open. The multi-layer adsorption model (the Freundlich model) will make the adsorption process more effective than the single layer (Langmuir model). In addition, this Freundlich adsorption model fits the mechanism proposed in this study (Figure 12) because the surface of soil dust particles has various active sites that provide many types of alternative interactions, namely hydrophilic-hydrophilic, hydrophobichydrophobic, wide range of polarity, and ion exchange (metathesis reaction). These types of interactions are supported by the presence of $\mathrm{Si}, \mathrm{Al}, \mathrm{Fe}$, and $\mathrm{Ca}$ compounds in soil dust and also the content of organic substances that have various functional groups. 
In Islamic teachings there are several examples of the use of soil as a cleaning agent, one of which is purifying najis objects affected by dog licking. In the fiqh of women, there is an obligation for women to wear long clothes and are even allowed to reach the ground because the najis adhere to the fabric will be purified by the next dust that is swept by the cloth. The nature of soil dust can adsorb organic materials effectively if without heating treatment (calcination). The heating treatment will decrease organic matter content and significantly reduce the adsorption power as in the case of MB adsorption in this study (Figures 3 and 4). The heating treatment at a temperature of $120{ }^{\circ} \mathrm{C}$ is to dry the soil dust sample, besides this temperature has been known as a temperature that can optimally liberate soil dust particles from the water on its surface and the crystalline water inside so as to maximize the pore volume and surface area of adsorption. Treatment at $120^{\circ} \mathrm{C}$ is expected to sterilize soil dust from pathogenic microorganisms. Therefore, dry dust soil is preferred because it meets the requirements for purification rather than wet soil dust or wet soil.

The function of soil minerals as a binding of organic substances is not new knowledge. All organic matter is returned to the soil, then can be brought into the air naturally or due to anthropogenic factors, but still returns to the soil because it is carried by rainwater or because it weighs according to the specific gravity and size of dust particles. Soil mineral particles have been known to control the carbon cycle in the atmosphere-lithosphere-biospherehydrosphere, so it can be said that the soil is a giant pool of all organic matter on earth [56]. In addition to the function of binding to organic substances, soil chemistry has a function as catalysts derived from iron minerals which oxidizes and reduces contaminants to form safe compounds and the oxidation states of arsenic, heavy metals, and organic substances [71].

Among all the practices of purification, it is estimated that only tayamum whose medium only has a symbolic meaning as a purifier, because very little amount of soil dust is used. In tayamum, soil dust is obtained only by one pat on the surface of the soil dust and it is still blown before rubbing into palms and face. In Tayamum, only the face and palms are rubbed. Both are the most open body parts to the open air in accordance with appropriate Muslim clothing.

Although tending to have symbolic meaning, tayamum can be a basic model in understanding soil dust as cleaning agent in reducing the source of germs. Of the 20 points on the surface of human skin, the face and hands have at most points (eight points) as permanent or temporary dwellings for trillions of bacteria, fungi, viruses, and small arthropods, and the two parts of the body are also points of the most diverse species (seven in hand and four in front of elevent species) [72]. These microbiome disorders, one of which is a weather factor [73], can cause microbiomas when colonizing, multiplying rapidly and causing disease [72]. In addition, abnormal sweat water production in the amount or variation of solutes causes the sweat water level to become high, being a nutrient for the growth of pathogenic microorganisms [74] or causing itching [75]. Likewise sweat has been recognized as a cause of worsening of skin diseases (atopic dermatitis) [76]. Sweat has been known to include dissolved ions $\left(\mathrm{Na}^{+}, \mathrm{K}^{+}, \mathrm{NH}_{4}^{+}, \mathrm{Cl}^{-}\right)$and a number of organic substances (cortisol, urea, lactate, neuropeptide, and interleukin [77] which will contribute nutrients to these microbiomas. Therefore, it can be understood that tayamum practice can reduce the risk of health problems for people who should not be exposed to water.

Considering the main mineral characteristics in soil dust, small amounts of organic matter, and adsorption power that has been discussed in this study, the practice of purifying Muslims by using soil dust or soil can be chemically understood to have the effect of cleaning up najis substances through the mechanism of adsorption and other chemical interactions. The benefits of purifying practices on body parts such as tayamum can also be understood from the 
latest findings about the potential and application of soil minerals. Silicate and aluminosilicate (clay) minerals, as well as other accompanying minerals, have been recognized as potential and are applied in the pharmaceutical and cosmetic fields [78] [79] [80] [81] [82] [83]. The practice of cleaning to objects that are affected by najis can also be understood through this research and a number of literature that mentions the potential and application of natural minerals and the results of their synthesis in wastewater treatment [84] [85] [86].

The teachings of Islam are known by adherents as the teachings of "rahmatan lil 'alamin" (from Arabic, which means having good for all nature). The phenomenon of the effectiveness of soil dust as an organic material adsorbent can be potentially developed to solve the problem of organic matter waste. Soil dust that has the potential to be developed is a type of soil dust that is considered waste collected from the results of cleaning rubbish. Waste can be sorted based on soil dust collected, then soil dust can be processed by heating to get a sterile adsorbent, free of all germs. Furthermore, calcined dry soil dust can be engineered with its chemical composition by desilication or dealumination to obtain the composition of $\mathrm{Si}, \mathrm{Al}, \mathrm{Fe}$, and $\mathrm{Ca}$ with optimal adsorption power. The use of soil dust to overcome the problem of environmental pollution will be far more efficient and environmentally friendly compared to minerals that are commercially mined.

\section{Conclusion}

From a number of experiments conducted, we found that soil dust has adsorption power for $\mathrm{MB}$ and $\mathrm{CuSO}_{4}$. $\mathrm{MB}$ adsorption is more effective than $\mathrm{CuSO}_{4}$. $\mathrm{MB}$ high adsorption power also occurs in dug soil samples and building wall dust. By using non-linear regression analysis (polynomial 2), the adsorption power is more easily understood as the effect of the composition of its elements, $\mathrm{Si}, \mathrm{Al}, \mathrm{Fe}$, and $\mathrm{Ca}$, compared to the mineral phase they contain. The adsorption model approaches the Freundlich model, which is a multilayer adsorption so that it can better explain the number of MB that can be adsorbed than the Langmuir model (single layer adsorption).

The high average adsorption ability of MB in soil dust $(89.69 \%)$ is relatively not different from soil $(80.45 \%)$ or building wall dust $(92.93 \%)$ in contact time for 2 minutes. Through this experimental evidence can be explained the relationship between the practice of purification of Muslims by using soil dust or soil because both absorb MB very well as a representation of organic compounds, as well as the ability of soil to store complex organic substances, such as humus. This analogy can be used because the representation of unclean substances, especially unclean ones classified as moderate to severe, is chemically an organic substance.

\section{Acknowledgement}

Dede Suhendar expressed his gratitude to the Research Institute of UIN Sunan Gunung Djati for the 2018 DIPA research funding.

\section{Rerefences}

[1] S. Ghazi, A. Sayigh and K. Ip, "Dust Effect on Flat Surfaces - A Review Paper," Renewable and Sustainable Energy Review, vol. 33, pp. 742-751, 2014.

[2] G. Sposito, The Surface Chemistry of Soils, New York: Oxford University Press, 1984. 
[3] A. R. Conklin, Jr., Introduction to Soil Chemistry: Analysis and Instrumentation, Hoboken: John Wiley \& Sons, 2005.

[4] H. H. Murray, Applied clay mineralogy: Occurrences, processing and application of kaolins, bentonites, palygorskite-sepiolite, and common clays, 1st penyunt., Oxford: Elsevier B.V., 2007.

[5] E. Bischoff, "Sources of Pollution of Indoor Air by Mite-Allergen-Containing House Dust," Env. Intl., vol. 15, pp. 181-192, 1989.

[6] N. D. Yordanov and I. Najdenova, "Selective Estimation of Soot in Home Dust by EPR Spectrometry," Spectrochimica Acta Part A, no. 60, pp. 1367-1370, 2004.

[7] R. M. Maertens, J. Bailey and P. A. White, "The Mutagenic Hazards of Settled House Dust: a Review," Mutation Research, no. 567, pp. 401-425, 2004.

[8] N. Moreno, A. Alastuey, X. Querola, B. Artin ano, A. Guerra, J. A. Luaces, A. Lorente and J. Basora, "Characterisation of Dust Material Emitted During Harbour Operations (HADA Project)," Atmospheric Environment, no. 41, pp. 6331-6343, 2007.

[9] P. Kaarakainen, H. Rintala, A. Vepsäläinen, A. Hyvärinen, A. Nevalainen and T. Meklin, "Microbial Content of House Dust Samples Determined with qPCR," Science of the Total Environment, no. 407, pp. 4673-4680, 2009.

[10] G. Shi, Z. Chen, S. Xu, J. Zhang, L. Wang, C. Bi and J. Teng, "Potentially Toxic Metal Contamination of Urban Soils and Roadside Dust in Shanghai, China," Environmental Pollution, no. 156, pp. 251-260, 2008.

[11] T. Salthammer, C. Fauck, T. Schripp, P. Meinlschmidt, S. Willenborg and H. -J. Moriske, "Effect of Particle Concentration and Semi-Volatile Organic Compounds on the Phenomenon of 'Black Magic Dust' in Dwellings," Building and Environment, no. 46, pp. 1880-1890, 2011.

[12] P. B. Kurt-Karakus, "Determination of Heavy Metals in Indoor Dust from Istanbul, Turkey: Estimation of the Health Risk," Enviromental International, no. 50, pp. 47-55, 2012.

[13] M. A. Calderón, J. Kleine-Tebbe, A. Linneberg, F. D. Blay, D. H. de Rojas, J. C. Virchow and P. Demoly, "House Dust Mite Respiratory Allergy: An Overview of Current Therapeutic Strategies," The Journal of Allergy and Clinical Immunology: In Practice, vol. 3, no. 6, pp. 843$855,2015$.

[14] A. M. Kamal, Ensiklopedi Fiqih Wanita, Jakarta: Pustaka Ibnu Katsir, 2016.

[15] A. Sarwat, Fiqih Thaharah, Jakarta: Du Center, 2009.

[16] A. P. Rutter, D. C. Snyder, J. J. Schauer, R. J. Sheesley, M. R. Olson and J. DeMinter, "Contributions of resuspended soil and road dust to organic carbon in fine particulate matter in the Midwestern US," Atmospheric Environment, vol. 45, pp. 514-518, 2011.

[17] A. Chappell, N. P. Webb, H. J. Butler, C. L. Strong, G. H. Mctainsh, J. F. Leys and R. A. V. Rossel, "Soil organic carbon dust emission: an omitted global source of atmospheric CO2," Global Change Biology, vol. 19, p. 3238-3244, 2013.

[18] R. Mikutta, G. E. Schaumann, D. Gildemeister, S. Bonneville, M. G. Kramer, J. Chorover, O. A. Chadwick and G. Guggenberger, "Biogeochemistry of mineral-organic associations across a long-term mineralogical soil gradient (0.3-4100 kyr), Hawaiian Islands," Geochimica et Cosmochimica Acta, vol. 73, pp. 2034-2060, 2009.

[19] T. Tanikawa, N. Yamashita, S. Aizawa, Y. Ohnuki, S. Yoshinaga and M. Takahashi, "Soil sulfur content and its spatial distribution in a small catchment covered by volcanic soil in the montane zone of central Japan," Geoderma, Vols. 197-198, pp. 1-8, 2013.

[20] K. Rida, S. Bouraoui and S. Hadnine, "Adsorption of methylene blue from aqueous solution by kaolin and zeolite," Applied Clay Science, vol. 83, pp. 99-105, 2013.

[21] D. A. Fungaro, M. Bruno and L. C. Grosche, "Adsorption and kinetic studies of methylene blue on zeolite synthesized from fly ash," Desalination and Water Treatment, vol. 2, pp. 231-239, 2009.

[22] Z. loannou, C. Karasawidis, A. Dimirkou and V. Antoniadis, "Adsorption of méthylène blue and methyl red dyes onto nnodified zeolites," Water Science and Technology, vol. 67, no. 5, pp. 1129-1136, 2013. 
[23] D. A. Fungaro, L. C. Grosche, A. S. Pinheiro, J. C. Izidoro and S. I. Borrely, "Adsorption of methylene blue from aqueous solution on zeolitic material and the improvement as toxicity removal to living organisms," Orbital the Electronic Journal of Chemistry, vol. 2, no. 3, pp. 235$247,2010$.

[24] M. D. Richards and C. G. Pope, "Adsorption of Methylene Blue from aqueous solutions by amorphous aluminosilicate gels and zeolite X," Journal of Chemical Society Faraday Transaction, vol. 92, pp. 317-323, 1996.

[25] M. Zendehdel, Z. Kalateh and H. Alikhani, "Efficiency evaluation of NaY zeolite and TiO2/NaY zeolite in removal of methylene blue dye from aqueous solutions," Iranian Journal of Environmental and Health Sciences and Engineering, vol. 8, no. 3, pp. 265-272, 2011.

[26] M. Canli, Y. Abali and S. U. Bayca, "Removal of methyleneblue by natural and Ca and Kexchanged zeolite treated with hyrogen peroxide," Physicochemical Problems of Mineral Processing, vol. 49, no. 2, pp. 481-496, 2013.

[27] Z. Aghanouri, M. Kashefialasl and A. H. Hasani, "Removal of Methylene Blue dye from aqueous solution by modified zeolite with copper oxide nanoparticles," International Journal of Advanced Biotechnology and Research, vol. 7, no. 3, pp. 410-1423, 2016.

[28] M. H. Dehghani, A. Dehghan, H. Alidadi, M. Dolatabadi, M. Mehrabpour and A. Converti, "Removal of methylene blue dye from aqueous solutions by a new chitosan-zeolite composite from shrimp waste; Kinetic and equilibrium study," Korean Journal of Chemical Engineering.

[29] Z. Sun, C. Li and D. Wu, "Removal ofmethylene blue from aqueous solution by adsorption onto zeolite synthesized from coal fly ash and its thermal regeneration," Journal of Chemical Technology and Biotechnology, vol. 85, pp. 845-850, 2010.

[30] J. H. Potgieter, "Adsorption of Methylene Blue on Activated Carbon: An Experiment Illustrating Both the Langmuir and Freundlich Isotherms," Journal of Chemical Education, vol. 68, no. 4, pp. 349-350, 1991.

[31] E. N. El Qada, S. J. Allen and G. M. Walker, "Adsorption of Methylene Blue onto activated carbon produced from steam activated bituminous coal: A study of equilibrium adsorption isotherm," Chemical Engineering Journal, vol. 124, pp. 103-110, 2006.

[32] D. Pathania, S. Sharma and P. Singh, "Removal of methylene blue by adsorption onto activated carbon developed from Ficus carica bast," Arabian Journal of Chemistry, vol. 10, pp. S1445S1451, 2017.

[33] M. M. R. Khan, M. W. Rahman, H. R. Ong, A. B. Ismail and C. K. Cheng, "Tea dust as a potential low-cost adsorbent for the removal of crystal violet from aqueous solution," Desalination and Water Treatment, 2015.

[34] D. L. Postai, C. A. Demarchi, F. Zanatta, D. C. C. Melo dan C. A. Rodrigues, "Adsorption of rhodamine B and methylene blue dyes using waste of seeds of Aleurites Moluccana, a low cost adsorbent," Alexandria Engineering Journal, vol. 55, pp. 1713-1723, 2016.

[35] U. J. Etim, S. A. Umoren and U. M. Eduok, "Coconut coir dust as a low cost adsorbent for the removal of cationic dye from aqueous solution," Journal of Saudi Chemical Society, vol. 20, pp. S67-S76, 2016.

[36] K. A. Adegoke and O. S. Bello, "Dye sequestration using agricultural wastes as adsorbents," Water Resources and Industry, vol. 12, pp. 8-24, 2015.

[37] K. S. Bharathi and S. T. Ramesh, "Removal of dyes using agricultural waste as low-cost adsorbents: a review," Applied Water Science, vol. 3, pp. 773-790, 2013.

[38] S. R. Taylor, "Abundance of chemical elements in the continental crust: a new table," Geochimica et Cosmochimica Acta, vol. 28, pp. 1273-1285, 1964.

[39] W. Feng, A. F. Plante, A. K. Aufdenkampe and J. Six, "Soil organic matter stability in organomineral complexes as a function of increasing C loading," Soil Biology and Biochemistry, vol. 69, pp. 398-405, 2014.

[40] R. Mikutta and K. Kaiser, "Organic matter bound to mineral surfaces: Resistance to chemical and biological oxidation," Soil Biology and Biochemistry, vol. 43, pp. 1738-1741, 2011. 
[41] T. B. Bruun, B. Elberling and B. T. Christensen, "Lability of soil organic carbon in tropical soils with different clay minerals," Soil Biology \& Biochemistry, vol. 42, pp. 888-895, 2010.

[42] Y.H. Shen, "Sorption of natural dissolved organic matter on soil," Chemosphere, vol. 38, no. 7, pp. 1505-1515, 1999.

[43] K. Heckman, C. R. Lawrence and J. W. Harden, "A sequential selective dissolution method to quantify storage and stability of organic carbon associated with $\mathrm{Al}$ and Fe hydroxide phases," Geoderma, vol. 312, pp. 24-35, 2018.

[44] A. R. Saidy, R. J. Smernik, J. A. Baldock, K. Kaiser and J. Sanderman, "The sorption of organic carbon onto differing clay minerals in the presence and absence of hydrous iron oxide," Geoderma, Vols. 209-210, pp. 15-21, 2013.

[45] M. Singh, B. Sarkar, B. Biswas, J. Churchman and N. S. Boland, "Adsorption-desorption behavior of dissolved organic carbon by soil clay fractions of varying mineralogy," Geoderma, vol. 280, pp. 47-56, 2016.

[46] J. J. Fitzgerald, A. I. Hamza, C. E. Bronnimann and S. F. Dec, "Solid-state 27Al and 29Si NMR studies of the reactivity of the aluminium-containing clay mineral kaolinite," Solid State lonics, Vols. 32-33, pp. 378-388, 1989.

[47] O. Allahdin, M. Wartel, G. Tricot, B. Revel and A. Boughriet, "Hydroxylation and dealumination of a metakaolinite-rich brick under acid conditions, and their influences on metal adsorption: One- and two-dimensional (1H, 27Al, 23Na, 29Si) MAS NMR, and FTIR studies," Microporous and Mesoporous Materials, vol. 226, pp. 360-368, 2016.

[48] H. Stach, U. Lohse, H. Thamm and W. Schirmer, "Adsorption equilibria of hydrocarbons on highly dealuminated zeolites," Zeolites, vol. 6, pp. 74-90, 1986.

[49] S. Navalon, M. Alvaro and H. Garcia, "Highly dealuminated Y zeolite as efficient adsorbent for the hydrophobic fraction from wastewater treatment plants effluents," Journal of Hazardous Materials, vol. 166, pp. 553-560, 2009.

[50] S. M. Auerbach, K. A. Carrado dan P. K. Dutta, Handbook of Zeolite Science and Technology, New York: Marcel Dekker, Inc., 2003.

[51] Y. H. Shen, "Sorption of non-ionic surfactants to soil: the role of soil mineral composition," Chemosphere, vol. 41, pp. 711-716, 2000.

[52] S. L. Brantley and N. P. Mellott, "Surface area and porosity of primary silicate minerals," American Mineralogist, vol. 85, pp. 1767-1783, 2000.

[53] V. Alekseenko and A. Alekseenko, "The abundances of chemical elements in urban soils," Journal of Geochemical Exploration, vol. 147, pp. 245-249, 2014.

[54] J. H. Potgietera and C. A. Strydomb, "Determination of the clay index of limestone with methylene blue adsorption using a UV-VIS spectrophotometric method," Cement and Concrete Research, vol. 29, pp. 1815-1817, 1999.

[55] V. Ramasamy and K. Anandalakshmi, "The determination of kaolinite clay content in limestones of western Tamil Nadu by methylene blue adsorption using UV-vis spectroscopy," Spectrochimica Acta Part A, vol. 70, pp. 25-29, 2008.

[56] U. Stockmann, M. A. Adams, J. W. Crawford, D. J. Field, N. Henakaarchchi, M. Jenkins, B. Minasny, A. B. McBratney, V. d. R. de Courcelle, K. Singh, I. Wheeler, L. Abbott, D. A. Angers, J. Baldock, M. Bird, P. C. Brookes, C. Chenu, J. D. Jastrow, R. Lal, J. Lehmann, A. G. O’Donnell, W. J. Parton, D. Whitehead and M. Zimmermann, "The knowns, known unknowns and unknowns of sequestration of soil organic carbon," Agriculture, Ecosystems and Environment, vol. 164, pp. 80-99, 2013.

[57] M. Shahbaz, Y. Kuzyakov and F. Heitkamp, "Decrease of soil organic matter stabilization with increasing inputs: Mechanisms and controls," Geoderma, vol. 304, pp. 76-82, 2017.

[58] J. C. Akan, S. I. Audu, Z. Mohammed and V. O. Ogugbuaja, "Assessment of Heavy Metals, pH, Organic Matter and Organic Carbon in Roadside Soils in Makurdi Metropolis, Benue State, Nigeria," Journal of Environmental Protection, vol. 4, pp. 618-628, 2013. 
[59] G. Rufyikiri, J. E. Dufey, R. Achard dan B. Delvaux , "Cation exchange capacity and aluminumcalcium-magnesium binding in roots of bananas cultivated in soils and in nutrient solutions," Communications in Soil Science and Plant Analysis, vol. 33, no. 5-6, pp. 991-1009, 2002.

[60] M. T. Iqbal, "Effect of Al compounds on soil pH and bioavailability of Al in two acid soil," Turkish Journal of Agriculture and Forestry, vol. 36, no. 6, pp. 720-728, 2012.

[61] D. J. Brautigan, P. Rengasamy and D. J. Chittleborough, "Aluminium speciation and phytotoxicity in alkaline soils," Plant and Soil, vol. 360, no. 1-2, 2012.

[62] A. R. Saidy, R. J. Smernik, J. A. Baldock, K. Kaiser, J. Sanderman and L. M. Macdonald, "Effects of clay mineralogy and hydrous iron oxides on labile organic carbon stabilisation," Geoderma, vol. 173-174, pp. 104-110, 2012.

[63] M. Singh, B. Sarkar, B. Biswas, N. S. Bolan and G. J. Churchman, "Relationship between soil clay mineralogy and carbon protection capacity as influenced by temperature and moisture," Soil Biology and Biochemistry, vol. 109, pp. 95-106, 2017.

[64] A. Carmo, L. Hundal and M. Thompson, "Sorption of Hydrophobic Organic Compounds by Soil Materials: Application of Unit Equivalent Freundlich Coefficients," Environmental, Science, and Technology, vol. 34, pp. 4363-4369, 2000.

[65] J. Toul, J. Bezděk, M. Kovářová, Z. Boháček, J. Hanák, J. Milička and P. Müller, "Sorption of hydrophobic organic pollutants on soils and sediments," Bulletin of Geosciences, vol. 78, no. 3, pp. 205-223, 2003.

[66] A. L. Tasca, F. Ghajeri and A. J. Fletcher, "Novel hydrophilic and hydrophobic amorphous silica: Characterization and adsorption of aqueous phase organic compounds," Adsorption Science and Technology, vol. 0, no. 0, pp. 1-16, 2017.

[67] N. S. Maurya and A. K. Mittal, "Applicability of Equilibrium Isotherm Models for the Biosorptive Uptakes in Comparison to Activated Carbon-Based Adsorption," Journal of Environmental Engineering, vol. 132, no. 12, pp. 1589-1599, 2006.

[68] A. Ebadi, J. S. Mohammadzadeh and A. Khudiev, "What is the correct form of BET isotherm for modeling liquid phase adsorption?," Adsorption, vol. 15, p. 65-73, 2009.

[69] S. Brunauer, P. H. Emmett and E. Teller, "Adsorption of Gases in Multimolecular Layers," Journal of American Chemical Society, vol. 60, no. 2, pp. 309-319, 1938.

[70] L. Yun-Ming, H. Cheng-Yong, M. M. Al Bakri and K. Hussin, "Structure and properties of claybased geopolymer cements; A review," Progress in Materials Science, vol. 83, p. 595-629, 2016.

[71] B. P. von der Heyden and A. N. Roychoudhury, "Application, chemical interaction and fate of iron minerals in polluted sediment and soils," Current Pollution Reports, vol. 1, no. 4, p. $265=279$.

[72] H. H. Kong and J. A. Segre, "Skin Microbiome: Looking Back to Move Forward," Journal of Investigative Dermatology, vol. 132, pp. 933-939, 2012.

[73] Q. Zhen, Y. Deng, Y. Wang, X. Wang, H. Zhang, X. Sun and Z. Ouyang, "Meteorological factors had more impact on airborne bacterial communities than air pollutants," Science of the Total Environment, Vols. 601-602, pp. 703-712, 2017.

[74] M. Troccaz, N. Gaïa, S. Beccucci, J. Schrenzel, I. Cayeux, C. Starkenmann and V. Lazarevic, "Mapping axillary microbiota responsible for body odours using a culture-independent approach," Microbiome, vol. 3, no. 3, 2015.

[75] H. Murota, K. Yamaga, E. Ono and I. Katayama, "Sweat in the pathogenesis of atopic dermatitis," Allergology International, vol. 67, pp. 455-459, 2018.

[76] T. Hiragun, M. Hiragun, K. Ishii, T. Kan and M. Hide, "Sweat allergy: extrinsic or intrinsic?," Journal of Dermatological Science, vol. 87, no. 1, pp. 3-9, 2017.

[77] Z. Sonner, E. Wilder, J. Heikenfeld, G. Kasting, F. Beyette, D. Swaile, F. Sherman, J. Joyce, J. Hagen, N. Kelley-Loughnane and R. Naik, "The microfluidics of the eccrine sweat gland, including biomarker partitioning, transport, and biosensing implications," Biomicrofluidics, vol. 9, no. 031301, 2015. 
[78] A. López-Galindo, C. Viseras and P. Cerezo, "Compositional, technical and safety specifications of clays to be used as pharmaceutical and cosmetic products," Applied Clay Science, vol. 36, pp. 51-63, 2007.

[79] G. M. Dário, G. G. da Silva, D. L. Gonçalves, P. Silveira, A. T. Junior, E. Angioletto and A. M. Bernardin, "Evaluation of the healing activity of therapeutic clay in rat skin wounds," Materials Science and Engineering C, vol. 43, pp. 109-116, 2014.

[ J. d. S. Favero, J. Parisotto-Peterle, V. Weiss-Angeli, R. N. Brandalise, L. B. Gomes, C. P. Bergmann and V. dos Santos, "Physical and chemical characterization and method for the decontamination of clays for application in cosmetics," Applied Clay Science, Vols. 124-125, pp. 252-259, 2016.

[81] M. I. Carretero and M. Pozo, "Clay and non-clay minerals in the pharmaceutical and cosmetic industries Part II. Active ingredients," Applied Clay Science, vol. 47, pp. 171-181, 2010.

[82] C. d. S. F. Gomes and J. B. P. Silva, "Minerals and clay minerals in medical geology," Applied Clay Science, vol. 36, pp. 4-21, 2007.

[83] J. D. D. Moraes, S. R. A. Bertolino, S. L. Cuffini, D. F. Ducart, P. E. Bretzke and G. R. Leonardi, "Clay minerals: properties and applications to dermocosmetic products and perspectives of natural raw materials for therapeutic purposes-a review," International Journal of Pharmaceutics, vol. 534, no. 1-2, pp. 213-219, 2017.

[84] H. T. Shu, D. Li, A. A. Scala and Y. H. Ma, "Adsorption of small organic pollutants from aqueous streams by aluminosilicate-based microporous materials," Separation and Purification Technology, vol. 11, no. 1, pp. 27-36, 1997.

[85] Y. I. Tarasevich, "Application of natural adsorbents and adsorption-active materials based thereon in the processes of water purification," in Studies in Surface Science and Catalysis, vol. 120, A. Dąbrowski, Ed., Amsterdam, Elsevier B.V., 1999, pp. 659-722.

[86] M. Alshaaer, B. El-Eswed, R. I. Yousef, F. Khalili and H. Rahier, "Development of functional geopolymers for water purification, and construction purposes," Journal of Saudi Chemical Society, vol. 20, no. Supplement 1, pp. S85-S92, 2016. 